US Army Corps

of Engineers ${ }_{\circledast}$

Engineer Research and

Development Center

Environmental Security Technology Certification Program (ESTCP)

\title{
Evaluation of Uncertainty in Constituent Input Parameters for Modeling the Fate of IMX-101 Components
}

Mark S. Dortch and Billy E. Johnson

May 2017

Aquifer dissolved concentration at MW161 down-gradient from Demo Area 2, MMR

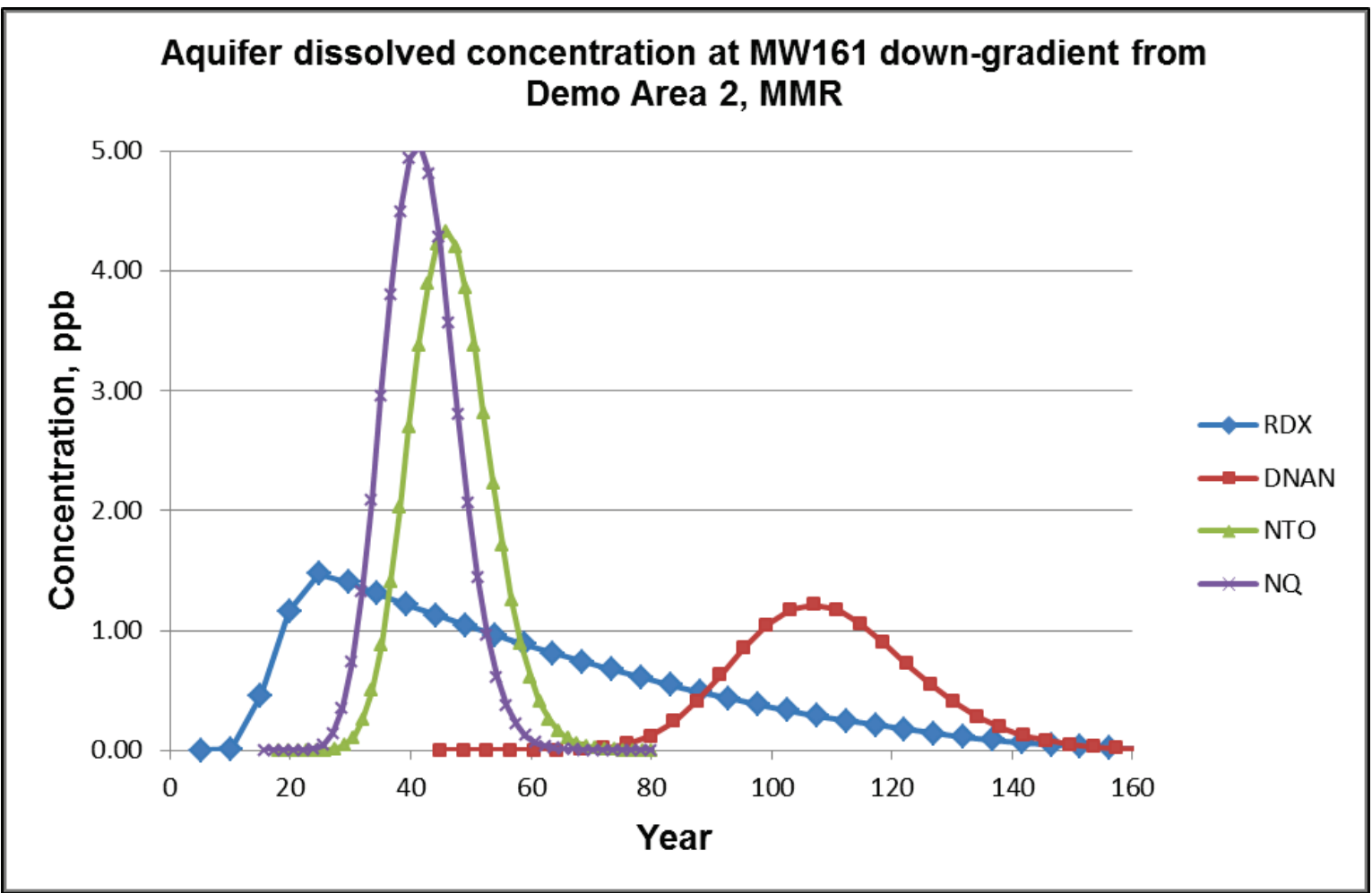


The U.S. Army Engineer Research and Development Center (ERDC) solves the nation's toughest engineering and environmental challenges. ERDC develops innovative solutions in civil and military engineering, geospatial sciences, water resources, and environmental sciences for the Army, the Department of Defense, civilian agencies, and our nation's public good. Find out more at www.erdc.usace.army.mil.

To search for other technical reports published by ERDC, visit the ERDC online library at http://acwc.sdp.sirsi.net/client/default. 


\section{Evaluation of Uncertainty in Constituent Input Parameters for Modeling the Fate of IMX-101 Components}

Billy E. Johnson

Environmental Laboratory

U.S. Army Engineer Research and Development Center

3909 Halls Ferry Road

Vicksburg, MS 39180-6199

Mark S. Dortch

Limno Tech, Inc.

501 Avis Drive

Ann Arbor, MI 48108

Final report

Approved for public release; distribution is unlimited.

Prepared for U.S. Army Corps of Engineers

Washington, DC 20314-1000

Under Project ER201435, "Field Demonstration and Validation of TREECS ${ }^{\text {TM }}$ and CTS for the Risk Assessment of Contaminants on DoD Ranges" 


\section{Abstract}

The Training Range Environmental Evaluation and Characterization System (TREECS ${ }^{\mathrm{TM}}$ ) was applied to a groundwater site and a surface water site to evaluate the sensitivity of the uncertain input properties (degradation rates and water-to-soil and water-to-sediment adsorption partitioning distribution coefficients, or $K_{d}$ values) on the fate of three emerging constituents (EC): DNAN, NTO, and NQ. These three EC are components of the new insensitive munitions explosive formulation IMX-101. The authors reviewed the literature and provided estimates of the expected degradation rates and $K_{d}$ values for the three EC. EC simulations were conducted for each site, and predicted concentrations in receiving groundwater and surface water were studied to draw conclusions regarding the sensitivity of the results to these uncertain inputs.

The applications revealed that, in general, surface water sites require much less accuracy for estimating soil and surface water EC degradation rates than do vadose zone and groundwater. Given the expected low $K_{d}$ values of the three EC, there is minimal need to accurately refine the EC $K_{d}$ estimates, particularly for surface water receptors. The authors concluded that future research should focus predominantly on determining degradation rates of EC in groundwater, vadose zone, and surface soil, in that order of priority.

DISCLAIMER: The contents of this report are not to be used for advertising, publication, or promotional purposes. Citation of trade names does not constitute an official endorsement or approval of the use of such commercial products. All product names and trademarks cited are the property of their respective owners. The findings of this report are not to be construed as an official Department of the Army position unless so designated by other authorized documents. 


\section{Contents}

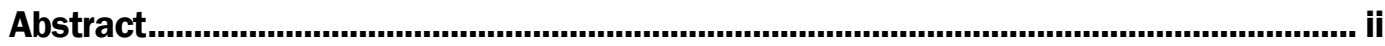

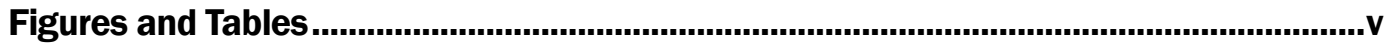

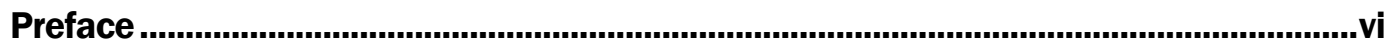

Abbreviations and Symbols .....................................................................................vii

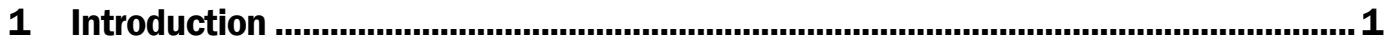

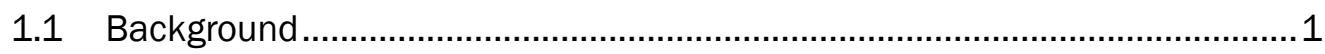

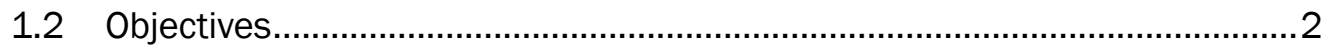

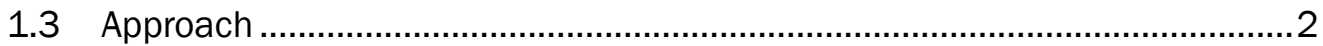

2 Physicochemical Properties ............................................................................................... 5

2.1 General chemical properties ................................................................. 5

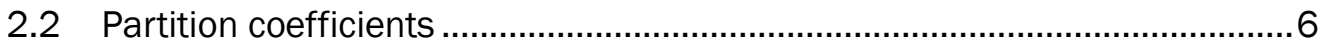

2.2.1 Partition coefficients for soil.......................................................................... 6

2.2.2 Partition coefficients for sediments .................................................................. 9

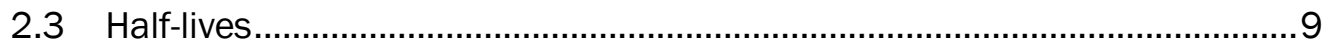

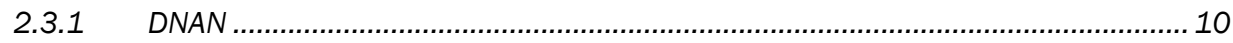

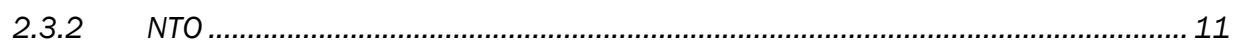

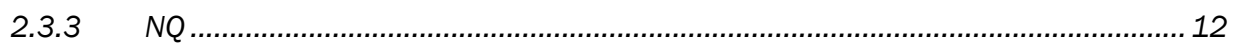

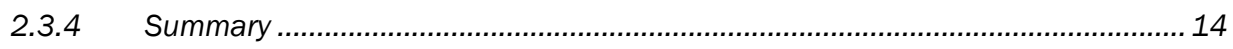

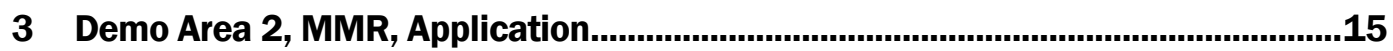

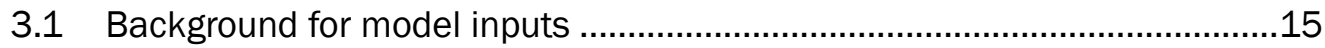

3.2 Baseline results .............................................................................. 16

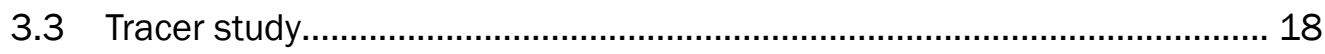

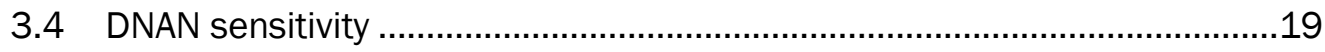

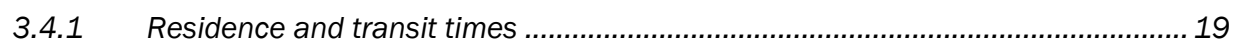

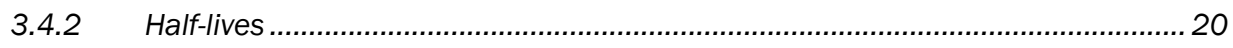

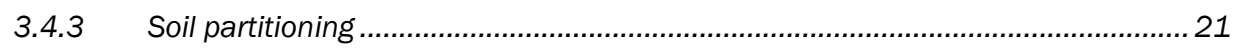

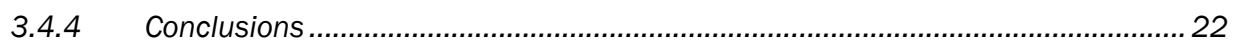

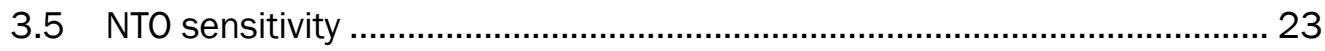

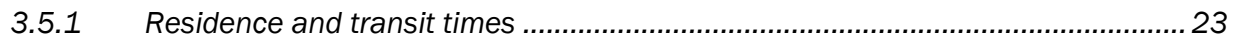

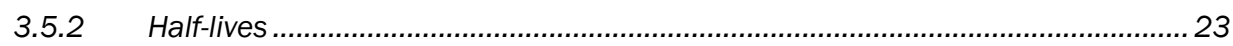

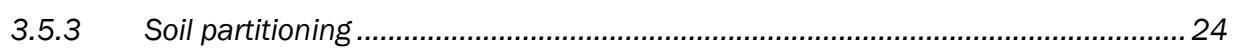

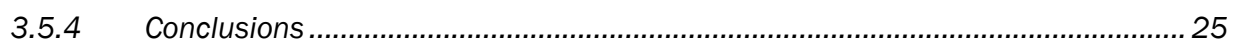

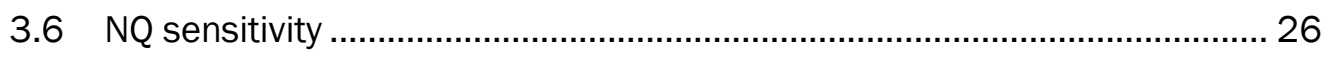

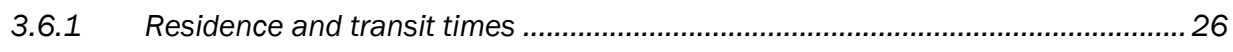

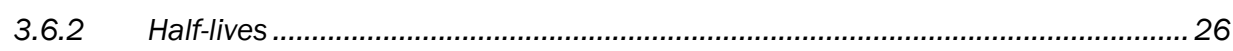

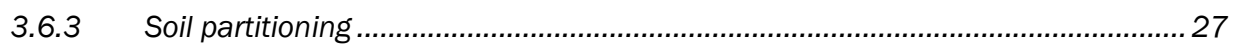

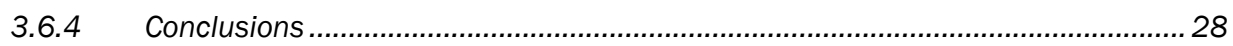




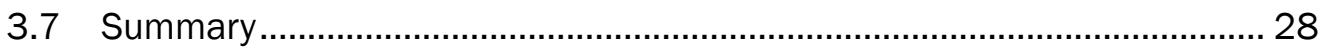

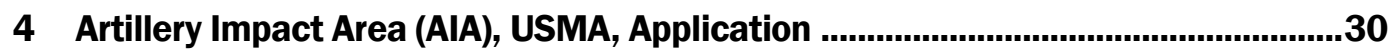

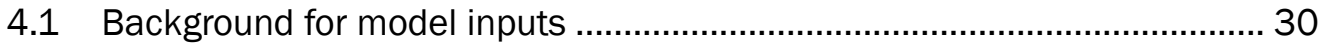

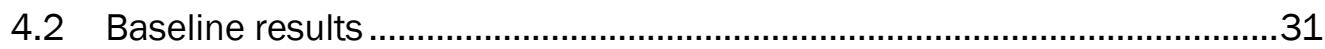

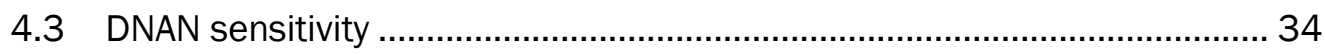

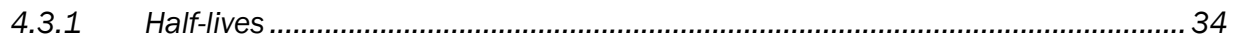

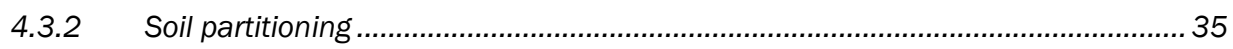

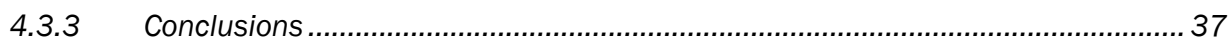

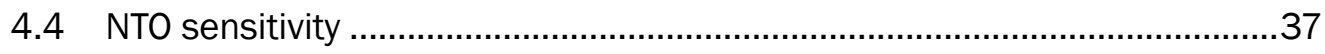

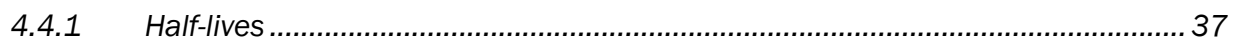

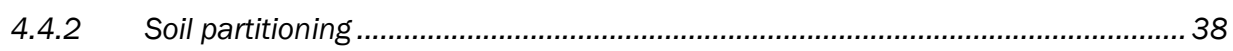

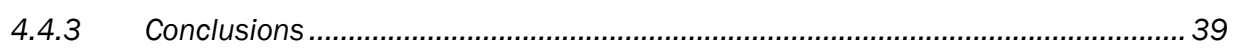

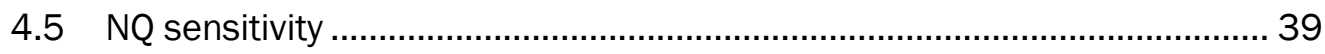

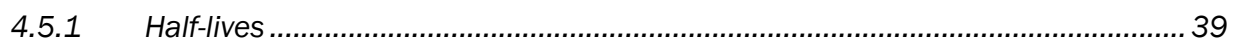

4.5.2 Soil partitioning ................................................................................... 41

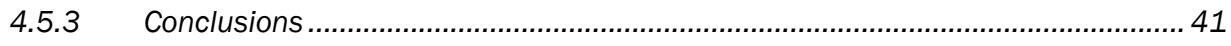

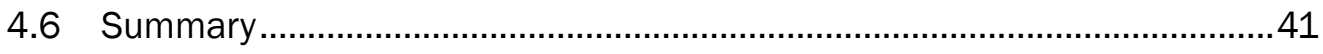

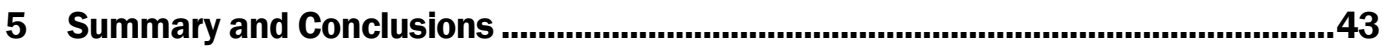

References......................................................................................................................45

Report Documentation Page 


\section{Figures and Tables}

\section{Figures}

Figure 1. Computed aquifer concentration of EC compared with RDX downgradient of Demo Area 2, MMR, for baseline conditions.

Figure 2. Computed aquifer concentration of EC compared with RDX down-

gradient of Demo Area 2, MMR, for 100-year HL for all constituents in all media.

Figure 3. Computed stream concentration of EC compared with RDX $50 \mathrm{~m}$ downstream of the AIA, USMA, for baseline conditions.

Figure 4. Computed stream concentration of EC compared with RDX 5000 m downstream of the AIA, USMA, for baseline conditions.

Figure 5. Computed stream concentration of DNAN $50 \mathrm{~m}$ downstream of the AIA, USMA, with $95 \%$ confidence bounds for uncertainty of soil HL compared to baseline conditions.

Figure 6. Computed stream concentration of DNAN $50 \mathrm{~m}$ downstream of the AIA, USMA, with $95 \%$ confidence bounds for uncertainty of soil $K_{d}$ values compared to baseline conditions.

Figure 7. Computed stream concentration of NTO $50 \mathrm{~m}$ downstream of the AIA, USMA, with $95 \%$ confidence bounds for uncertainty of soil HL compared to baseline conditions.

Figure 8. Computed stream concentration of NQ 50 m downstream of the AIA, USMA, with $95 \%$ confidence bounds for uncertainty of soil HL compared to baseline conditions.

\section{Tables}

Table 1. Basic properties for the three EC........................................................................ 5

Table 2. Fairly well-known chemical properties for the three EC...........................................6

Table 3. Estimated soil $K_{d}$ values (L/kg) for two study sites. ............................................... 8

Table 4. Estimated surface water TSS and benthic sediment $K_{d}$ values (L/kg) for

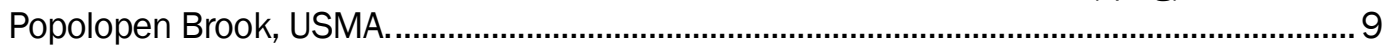

Table 5. Recommended half-lives (years) of EC. ……....................................................14

Table 6. Sensitivity of aquifer EC concentrations to inputs for soil partitioning and degradation.

Table 7. Sensitivity of surface water stream concentrations for three EC to inputs for degradation and partitioning. 


\section{Preface}

This study was funded by the Environmental Security Technology Certification Program (ESTCP) under the Environmental Restoration work topic area as ESTCP Project Number ER-201435, "Field Demonstration and Validation of TREECS ${ }^{\mathrm{TM}}$ and CTS for the Risk Assessment of Contaminants on Department of Defense Ranges.” Dr. Andrea Leeson was the Deputy Director of ESTCP and the Environmental Restoration Program Manager.

The work was performed by the Water Quality and Contaminant Modeling Branch (WQCMB), Environmental Processes and Engineering Division (EP), Environmental Laboratory (EL) of the Engineer Research and Development Center (ERDC). At the time of publication, Dr. Dorothy Tillman was Chief, WQCMB; Warren P. Lorentz was Chief, EP; and Dr. Elizabeth Ferguson was the Technical Director of military materials in the environment. Dr. Jack E. Davis was Deputy Director and Dr. Beth C. Fleming was Director of the EL.

COL Bryan S. Green was the Commander of ERDC and Dr. David W. Pittman was the Director of ERDC. 


\section{Abbreviations and Symbols}

\section{Acronyms and Abbreviations}

\begin{tabular}{|c|c|}
\hline AIA & artillery impact area \\
\hline $\mathrm{AOI}$ & area of interest, such as HE impact area \\
\hline $\mathrm{ARCDB}$ & Army Range Constituent Database within TREECS ${ }^{\mathrm{TM}}$ \\
\hline $\mathrm{BMP}(\mathrm{s})$ & best management practice(s) \\
\hline CASRN & Chemical Abstract Service Registry Number \\
\hline CMS & Contaminant Model for Streams \\
\hline CTS & Chemical Transformation Simulator \\
\hline Demo & Demolition \\
\hline DNAN & IM explosive component, 2,4-dinitroanisole \\
\hline DoD & Department of Defense \\
\hline $\mathrm{EC}$ & emerging contaminants or constituents \\
\hline EFS & Environmental Fate Simulator, now referred to as CTS \\
\hline $\mathrm{EL}$ & Environmental Laboratory \\
\hline EPA & U.S. Environmental Protection Agency \\
\hline EPI & Estimation Program Interface \\
\hline $\mathrm{EP}$ & Environmental Processes and Engineering Division \\
\hline ERDC & Engineer Research and Development Center \\
\hline ESTCP & Environmental Security Technology Certification Program \\
\hline $\mathrm{HE}$ & high explosives \\
\hline HLC & Henry's Law Constant, units of atm-m3/mole \\
\hline IM & insensitive munitions \\
\hline LCL & lower confidence limit for uncertainty analysis \\
\hline $\mathrm{MC}$ & munitions constituents, such as the HE RDX \\
\hline $\mathrm{MCB}$ & Marine Corps Base \\
\hline MEPAS & Multimedia Environmental Pollutant Assessment System \\
\hline MMR & Massachusetts Military Reservation \\
\hline NTO & IM explosive component, 3-nitro-1,2,4-triazol-5-one \\
\hline NQ & IM explosive component, nitroguanidine \\
\hline $\mathrm{OC}$ & organic carbon \\
\hline $\mathrm{ppb}$ & $\begin{array}{l}\text { parts per billion as concentration of a constituent in water, } \\
\text { same as } \mu \mathrm{g} / \mathrm{L}\end{array}$ \\
\hline RDX & $\begin{array}{l}\text { Royal Demolition Explosive, a high explosive, hexahydro- } \\
\text { 1,3,5-trinitro-1,3,5-triazine }\end{array}$ \\
\hline TREECS $^{\text {TM }}$ & $\begin{array}{l}\text { Training Range Environmental Evaluation and Characteriza- } \\
\text { tion System }\end{array}$ \\
\hline TSS & total suspended solids \\
\hline UCL & upper confidence limit for uncertainty analysis \\
\hline UI(s) & user interface(s) for entering and viewing model inputs \\
\hline USMA & U.S. Military Academy \\
\hline WQCMB & Water Quality and Contaminant Modeling Branch \\
\hline ZIA & Zulu impact area of Camp Pendleton \\
\hline
\end{tabular}




\section{Symbols}

$K_{d} \quad$ sorption distribution coefficient for partitioning an MC between soil particles and water, $\mathrm{L} / \mathrm{kg}$

$K_{o c} \quad$ organic carbon normalized soil-water sorption partition coefficient, L/kg

Kow octanol-water sorption partition coefficient, $\mathrm{mL} / \mathrm{mL}$

$R D \quad$ relative difference in $K_{d}$ values used to estimate range in $K_{d}$ values, $\mathrm{L} / \mathrm{kg}$ 


\section{Introduction}

\subsection{Background}

The Training Range Environmental Evaluation and Characterization System (TREECS ${ }^{\mathrm{TM}}$ 1) was developed for the Army to forecast the fate of and risk from munitions constituents (MC), such as high explosives (HE) and metals, within and transported from firing/training ranges to surface water and groundwater. TREECS ${ }^{\mathrm{TM}}$ consists of time-varying contaminant fate/transport models for soil, vadose zone, groundwater, and surface water; these models forecast MC export from ranges and the resulting concentrations in each medium. TREECS ${ }^{\mathrm{TM}}$ allows Department of Defense (DoD) training range managers and/or their environmental specialists to rapidly assess off-site MC migration as well as other contaminant migration to determine whether and when range operations could pose risks to human and ecological receptors down-gradient of ranges. Additionally, TREECS $^{\mathrm{TM}}$ can be used to evaluate Green Range Best Management Practice (BMP) alternatives where concentrations are presently or are predicted in the future to exceed protective action limits for human and ecological health. A detailed description of TREECS ${ }^{\mathrm{TM}}$, as well as its performance, is provided by Dortch et al. (2013).

The physicochemical properties of the $\mathrm{MC}$ or contaminants (including emerging contaminants, or EC) of interest are required for TREECS ${ }^{\mathrm{TM}}$ application. Such properties include, for example, molecular weight, solubility, solid-phase density, sorption partitioning coefficients, Henry's Law constant, and degradation rates. Although TREECS ${ }^{\mathrm{TM}}$ contains three separate databases for constituent physicochemical properties, there are data gaps within these databases.

The Chemical Transformation Simulator (CTS), previously called the Environmental Fate Simulator ${ }^{2}$ (EFS), was developed by the US Environmental Protection Agency (EPA) to provide physicochemical properties of com-

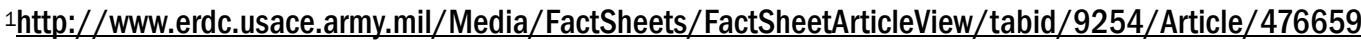
/training-range-environmental-evaluation-characterization-system.aspx

2 http://www.epa.gov/athens/research/efs indepth.html
} 
plex organic chemicals. CTS has capabilities for estimating properties in the absence of experimentally obtained properties; thus, CTS can help fill data gaps for properties, particularly for emerging contaminants with limited experimental data.

The Environmental Security Technology Certification Program (ESTCP) funded the work presented in this report. The work focused on applying TREECS $^{\mathrm{TM}}$ (with supplemental information provided by CTS) to DoD study sites to validate the capability to predict MC concentrations in receiving waters down-gradient of training/firing ranges. The effort also demonstrated the utility of the modeling systems for forecasting the fate of $\mathrm{MC}$ - as well as of EC - within and off-site of DoD installations. The bulk of this work is reported in a separate report (Dortch et al. 2017). As a side benefit of this work, the present report documents the utility of TREECS ${ }^{\mathrm{TM}}$ for evaluating EC fate and provides important information regarding the sensitivity of EC input parameters and the effects of their uncertainty on field concentrations.

\subsection{Objectives}

The objectives of the study reported herein were to use TREECS ${ }^{\mathrm{TM}}$ to evaluate the sensitivity of input properties for emerging constituent components making up the new insensitive munitions (IM) explosive formulation IMX-101 and to assess the effects of property uncertainty on the fate of those $\mathrm{EC}$ in receiving water down-gradient of usage areas.

\subsection{Approach}

Three sites were selected for this ESTCP project as detailed in the ESTCP project Site Selection Memo. The three study sites are: Demolition (Demo) Area 2 of Camp Edwards, Massachusetts Military Reservation (MMR), MA; the Artillery Impact Area (AIA) of the U.S. Military Academy (USMA), West Point, NY; and the Zulu Impact Area (ZIA) of Marine Corps Base (MCB) Camp Pendleton, CA. Two of these sites, Demo Area 2 of MMR and the AIA of USMA (West Point), were used for further study of IMX-101 components as presented in this report. Surface soil, vadose zone, and groundwater were modeled for Demo Area 2 of MMR. Surface soil and surface water (Popolopen Brook) were modeled for the AIA at West Point. Thus, these two sites provide both types of receiving water (groundwater and surface water) that can exist down-gradient of firing ranges. 
Insensitive munitions (IM) contain explosive constituents that are less sensitive to heat and shock. The IM explosive formulation referred to as IMX-101 is featured in the present study. IMX-101 contains three EC: 2, 4dinitroanisole (DNAN); 3-nitro-1, 2, 4-triazol-5-one (NTO); and nitroguanidine (NQ). Thus, these three EC were modeled with TREECS ${ }^{\mathrm{TM}}$ for the two study sites, Demo Area 2 of MMR, and AIA of USMA.

As stated previously, physicochemcial properties must be provided for each explosive constituent for modeling the constituent fate in various media. There is relatively high confidence in values for some of the properties, including molecular weight, water solubility, and solid phase density for the three EC. Although there is some uncertainty in the values of Henry's Law Constant (HLC), values for the three EC are low enough that volatilization is a minor fate process. Likewise, diffusivity in air, which is an input used to compute volatilization, has low importance for the three EC. The molecular diffusivity in water is required, but values can be readily estimated (Hayduk and Laudie 1974).

The organic carbon normalized soil-water sorption partition coefficient, $K_{o c}, \mathrm{~L} / \mathrm{kg}$, and the octanol-water sorption partition coefficient, $K_{o w}$, $\mathrm{mL} / \mathrm{mL}$, are used to estimate the constituent sorption partitioning distribution coefficients, $K_{d}(\mathrm{~L} / \mathrm{kg})$, for soil - water and sediment - water, respectively. However, $K_{d}$ values for some chemicals depend more on other media characteristics, such as pH for NTO, rather than organic carbon, which relates to the need for $K_{o c}$ and/or $K_{o w}$ values. Thus, the true need is an estimate of constituent $K_{d}$ values for soil and sediment. The remaining property required for model input is usually the most important and the poorest known, and it is the constituent degradation rate or half-life in each medium (soil, groundwater, and surface water). In summary, the two types of inputs that are quite important and the most uncertain are media $K_{d}$ values and degradation rates (or half-lives). Thus, sensitivity testing was conducted for these two inputs for each EC in each medium to evaluate their importance with regard to their fate and concentration in receiving waters.

All site-specific inputs required for modeling, such as soil characteristics, meteorology, and hydrology, were the same as those presented by Dortch et al. (2017) for each study site. The source loading rate (grams/year) for each EC was set to the same value as that determined for the explosive component RDX for each study site. The General Soil Source Zone option 
in the Operational Inputs/Site Conditions screen of TREECS ${ }^{\mathrm{TM}}$ was used for specifying the site loading rate for each EC.

It was necessary to establish input values for all physicochemical properties for the three EC prior to conducting any modeling. Thus, the next chapter of this report is devoted to the discussion of these inputs. 


\section{Physicochemical Properties}

The discussion of values for physicochemical properties is divided into three categories: general chemical properties, partition coefficients, and half-lives. The general chemical properties are held constant for each application presented herein, but the partition coefficients and half-lives are varied due to their much greater uncertainty.

\subsection{General chemical properties}

The general chemical properties are divided here into two groups, those that are well-known basic properties, and those that are fairly well-known with a range of values. The well-known, basic properties include molecular formula, molecular weight, molecular diffusivity in water, and solid phase density. Values of these properties for each EC are shown in Table 1. The molecular diffusivity in water was computed by the method of Hayduk and Laudie (1974). The molecular diffusivity in air was computed by the method of Fuller et al. (1966). The Chemical Abstract Service Registry Number (CASRN) for each EC is also shown in Table 1. All values in Table 1 were obtained from the TREECS ${ }^{\mathrm{TM}}$ Army Range Constituent Database (ARCDB), which provides the source references for each value. Many of the values within ARCDB were obtained from the EPI Suite software developed by the US Environmental Protection Agency's Office of Pollution Prevention Toxics and Syracuse Research Corporation (http://www.epa.gov/oppt/exposure/pubs/episuitedl.htm). EPI Suite is also part of CTS.

Table 1. Basic properties for the three EC.

\begin{tabular}{|l|c|c|c|c|c|c|}
\hline \multicolumn{1}{|c|}{$\begin{array}{c}\text { Emerging } \\
\text { Constituent }\end{array}$} & CASRN & $\begin{array}{c}\text { Molecular } \\
\text { formula }\end{array}$ & $\begin{array}{c}\text { Molecular } \\
\text { weight }\end{array}$ & $\begin{array}{c}\text { Molecular } \\
\text { diffusivity } \\
\text { in water, } \\
\text { cm²/sec }\end{array}$ & $\begin{array}{c}\text { Molecular } \\
\text { diffusivity } \\
\text { in air, } \\
\text { cm²/sec }\end{array}$ & $\begin{array}{c}\text { Solid } \\
\text { phase } \\
\text { density, } \\
\text { g/cm }\end{array}$ \\
\hline $\begin{array}{l}2,4- \\
\text { dinitroanisol } \\
\text { (DNAN) }\end{array}$ & $119-27-7$ & $\mathrm{C}_{7} \mathrm{H}_{6} \mathrm{~N}_{2} \mathrm{O}_{5}$ & 198 & $6.2 \mathrm{E}-6$ & 0.065 & 1.34 \\
\hline $\begin{array}{l}\text { nitrotiazolone } \\
\text { (NTO) }\end{array}$ & $932-64-9$ & $\mathrm{C}_{2} \mathrm{H}_{2} \mathrm{~N}_{4} \mathrm{O}_{3}$ & 130 & $8.5 \mathrm{E}-6$ & 0.1 & 1.93 \\
\hline $\begin{array}{l}\text { nitroguanidine } \\
\text { (NQ) }\end{array}$ & $556-88-7$ & $\mathrm{CH}_{4} \mathrm{~N}_{4} \mathrm{O}_{2}$ & 104 & $8.4 \mathrm{E}-6$ & 0.1 & 1.72 \\
\hline
\end{tabular}


The fairly well-known chemical properties required within TREECS ${ }^{\mathrm{TM}}$ include water solubility, HLC, $K_{o w}$, and $K_{o c}$; the latter two properties are only needed for estimating respectively the soil and sediment partitioning coefficients, which are addressed directly in this chapter. The ARCDB provides values for all four of these properties, and in some cases, multiple values are provided so that the user must select which one to use in the application. Source references are provided for each value. The recommended values used for the applications presented in this report are shown in Table 2.

Table 2. Fairly well-known chemical properties for the three EC.

\begin{tabular}{|l|c|c|c|c|}
\hline $\begin{array}{c}\text { Emerging } \\
\text { Constituent }\end{array}$ & $\begin{array}{c}\text { Solubility, } \\
\mathrm{mg} / \mathrm{L}\end{array}$ & $\begin{array}{c}\mathrm{HLC}, \\
\text { atm- } \\
\mathrm{m}^{3} / \mathrm{mole}\end{array}$ & $\begin{array}{c}\text { Kow, } \\
\mathrm{mL} / \mathrm{mL}\end{array}$ & $\begin{array}{c}\text { Koc, } \\
\text { L/kg }\end{array}$ \\
\hline $\begin{array}{l}\text { 2,4- } \\
\text { dinitroanisol } \\
\text { (DNAN) }\end{array}$ & 276 & $3.01 \mathrm{E}-7$ & 43.6 & 230 \\
\hline $\begin{array}{l}\text { nitrotiazolone } \\
\text { (NTO) }\end{array}$ & 16,600 & $4.07 \mathrm{E}-13$ & 2.34 & 0.41 \\
\hline $\begin{array}{l}\text { nitroguanidine } \\
\text { (NQ) }\end{array}$ & 2,600 & $4.49 \mathrm{E}-12$ & 0.13 & 12 \\
\hline
\end{tabular}

\subsection{Partition coefficients}

There are two classes of partition coefficients required for the two applications presented herein, soil-water and sediment-water. The reversible, equilibrium, linear, partitioning distribution coefficient, $K_{d}(\mathrm{~L} / \mathrm{kg})$, is used in the TREECS ${ }^{\mathrm{TM}}$ fate models for various media. Values for EC partition coefficients for the two classes, soil and sediment, are discussed in the respective sections below.

\subsubsection{Partition coefficients for soil}

Soil can be further divided into surficial soil and deeper soil, including the vadose zone and groundwater. Thus, different $K_{d}$ values can be required for each of these three medium, but the variation is usually due to a characteristic of the medium, such as the organic matter content, the $\mathrm{pH}$, or some other medium feature. Sediments refer to solids within the benthic bed and those that are suspended in the water column of surface waters. Thus, different $K_{d}$ values can be required for benthic and suspended sedi- 
ments, and the variation is usually due to a characteristic of the sediments, such as the organic carbon content and the solids concentration. Partition coefficients can vary widely for a specific chemical and can be very sitespecific. Thus, there can be much uncertainty associated with their values.

Scientific literature was used to obtain estimates of $K_{d}$ values in soils for the three EC. No information was found for $K_{d}$ values in sediments for the three EC, so sediment values had to be extended from soil values.

The most comprehensive study of partitioning of DNAN and NTO in soil was conducted by Dontsova et al. (2014a). Empirical relationships for estimating $K_{d}$ values for DNAN and NTO in soils are provided by Dontsova et al. (2014b), where $K_{d}(\mathrm{~L} / \mathrm{kg})$ for DNAN depends on the soil percent of organic carbon (OC), and $K_{d}(\mathrm{~L} / \mathrm{kg})$ for NTO depends on soil $\mathrm{pH}$. These two relationships for $K_{d}$ values of DNAN and NTO are

$$
\begin{gathered}
K_{d}(D N A N)=1.0+1.1 O C \\
K_{d}(N T O)=1.07-0.12 p H
\end{gathered}
$$

TREECS ${ }^{\mathrm{TM}}$ has a tool for estimating soil $K_{d}$ values given $K_{o c}$, the soil texture (percent sand, silt, and clay), and the percent organic matter content. However, the predicted DNAN $K_{d}$ values using this tool were about double the measured values (average relative error of $116 \%$ ) for the 11 soils studied by Dontsova et al. (2014a). Use of Equation 1 provides much greater accuracy for estimating soil $K_{d}$ values for DNAN, with an average relative error of $20 \%$.

The soil OC data presented by Dontsova et al. (2014a) for 11 different soils was used with Equation 1 to compute DNAN soil $K_{d}$ values. The measured $K_{d}$ values were subtracted from the computed values and divided by the computed value to produce a relative difference for each soil. Then the maximum and minimum relative differences $(R D)$ for the 11 soils were retained to estimate the range in $K_{d}$ values for a given OC. The maximum and minimum $R D$ in DNAN $K_{d}$ values for the 11 soils were 0.56 and -0.56, respectively. The $K_{d}$ values for each of the two study sites were determined using the soil OC values for each site. The range in site DNAN $K_{d}$ values for soil was then estimated by adding to the computed site $K_{d}$ value the products of the maximum and minimum $R D$ times the computed site $K_{d}$ value as follows, 


$$
K_{d}(\max , \min )=K_{d}+R D(\max , \min ) K_{d}
$$

where the $K_{d}$ values in Equation 3 are computed from Equation 1 using the site $\mathrm{OC}$, and $R D$ (max, $\min$ ) is the maximum (or minimum) $R D$ for the 11 soils.

The same approach described above for estimating the range of DNAN soil $K_{d}$ values was used for NTO, except that the soil pH for the 11 soils was used with Equation 2. The maximum and minimum relative differences in NTO $K_{d}$ values for the 11 soils were 0.76 and -0.3, respectively. The range in site NTO $K_{d}$ values for soil was then estimated by adding to the computed site $K_{d}$ value (using Equation 2) the products of the maximum and minimum $R D$ times the computed site $K_{d}$ value (see Equation 3).

With the measured soil $\mathrm{OC}$ and $\mathrm{pH}$ values for the two study sites as reported by Dortch et al. (2017), the recommended mean, maximum, and minimum $K_{d}$ values for surficial and deeper soils were estimated using Equations $1-3$. The surface and subsurface soil OC at Demo Area 2, MMR, are 0.68 and $0.068 \%$, respectively, and the surface and subsurface $\mathrm{pH}$ values are 4.6 and 5.9, respectively. The surface soil OC and pH at AIA, USMA, are $1.8 \%$ and 5.5, respectively. Subsurface soil values were not required since groundwater was not modeled at USMA. The resulting $K_{d}$ values are summarized in Table 3.

Table 3. Estimated soil $K_{d}$ values (L/ kg) for two study sites.

\begin{tabular}{|l||c|c|c|c|c|c||}
\hline \hline Site / EC & $\begin{array}{c}\text { Mean } \\
\text { surface } \\
\text { soil } K_{d}\end{array}$ & $\begin{array}{c}\text { Maximum } \\
\text { surface } \\
\text { soil } K_{d}\end{array}$ & $\begin{array}{c}\text { Minimum } \\
\text { surface } \\
\text { soil } K_{d}\end{array}$ & $\begin{array}{c}\text { Mean } \\
\text { subsurface } \\
\text { soil } K_{d}\end{array}$ & $\begin{array}{c}\text { Maximum } \\
\text { subsurface } \\
\text { soil } K_{d}\end{array}$ & $\begin{array}{c}\text { Minimum } \\
\text { subsurface } \\
\text { soil } K_{d}\end{array}$ \\
\hline \multicolumn{7}{|l|}{ Demo Area 2 , MMR } \\
\hline DNAN & 1.75 & 2.73 & 0.78 & 1.07 & 1.68 & 0.48 \\
\hline NTO & 0.52 & 0.91 & 0.36 & 0.36 & 0.64 & 0.25 \\
\hline NQ & 0.3 & 0.6 & 0.1 & 0.3 & 0.6 & 0.1 \\
\hline AIA, USMA & & & & & \\
\hline DNAN & 2.98 & 4.66 & 1.33 & NA & NA & NA \\
\hline NTO & 0.41 & 0.72 & 0.29 & NA & NA & NA \\
\hline NQ & 0.3 & 0.6 & 0.1 & NA & NA & NA \\
\hline
\end{tabular}

NA is not applicable 
Taylor et al. (2012) found that soil $K_{d}$ values for NQ varied from 0.24 to $0.6 \mathrm{~L} / \mathrm{kg}$ for three soils. These studies showed no correlation to OC. Haag et al. (1990) stated that $K_{d}$ values were less than $0.1 \mathrm{~L} / \mathrm{kg}$ for two soil measurements they conducted. In studies by Brannon et al. (2004), NQ partition coefficients were very low, ranging from 0.15 to $0.43 \mathrm{~L} / \mathrm{Kg}$. It is concluded that $K_{d}$ values of NQ in soil vary from about 0.1 to 0.6 , with a recommended mean value of about $0.3 \mathrm{~L} / \mathrm{kg}$.

\subsubsection{Partition coefficients for sediments}

The partition coefficients for DNAN and NTO in surface water sediments were estimated based upon the same approach used for soils; i.e., Equations $1-3$. The total suspended sediment (TSS) and benthic sediment OC in Popolopen Brook down-gradient of the AIA, USMA, were both assumed to be $2 \%$, which is close to the soil OC and is a typical value for surface water sediments. No measured values for sediment OC in Popolopen Brook were available. The pH in Popolopen Brook as reported by ATC (2004) is 7.2. These values were used to compute surface water sediment DNAN and NTO $K_{d}$ values as summarized in Table 4.

Table 4. Estimated surface water TSS and benthic sediment $K_{d}$ values (L/kg) for Popolopen Brook, USMA.

\begin{tabular}{|l|c|c|c|}
\hline \multicolumn{1}{|c|}{ EC } & Mean $K_{d}$ & $\begin{array}{c}\text { Maximum } \\
K_{d}\end{array}$ & $\begin{array}{c}\text { Minimum } \\
K_{d}\end{array}$ \\
\hline DNAN & 3.2 & 5.0 & 1.42 \\
\hline NTO & 0.21 & 0.36 & 0.14 \\
\hline NQ & 0.3 & 0.6 & 0.1 \\
\hline
\end{tabular}

The same $K_{d}$ values of NQ in soil were used for surface water sediments; i.e., a recommended mean value of $0.3 \mathrm{~L} / \mathrm{kg}$ with a range of from 0.1 to 0.6 $\mathrm{L} / \mathrm{kg}$.

\subsection{Half-lives}

As with partition coefficients, the scientific literature was used to obtain estimates of degradation rates, or half-lives, for DNAN, NTO, and NQ in soil and water. Most of the available information was for soil, however. Information obtained for half-lives of each of the three EC are discussed in the respective sections below. 


\subsubsection{DNAN}

Half-life of DNAN due to photo-transformation, via mostly photooxidation, is about 0.7 days (Rao et al. 2013). Thus, photo-oxidation can be a major loss mechanism in surface water. Alkaline hydrolysis can also readily degrade DNAN (Salter-Blanc et al. 2013).

Degradation half-lives for DNAN (as well as NTO) in soil on the order of a few days to a month or two were reported by Dontsova et al. (2014a) for their batch laboratory studies. These results seem to be in contradiction to the slow rate of degradation of DNAN in soil presented by Perreault et al. (2012a) for an unamended microcosm, where a half-life of about 0.5 years was estimated. This longer half-life is probably more representative of degradation in natural aerobic soil and groundwater environments, such as Demo Area 2.

Field et al. (2014) reported the biotransformation of DNAN and NTO in soil cultures. Each soil type was tested under aerobic incubations without any supplemental substrate and under anaerobic conditions with $\mathrm{H}_{2}$ as an electron donating substrate. Neither DNAN nor NTO were significantly degraded in any soil under aerobic conditions. However, there was a slight decrease in DNAN concentration over 60 days, indicating a half-life of roughly 2.2 years. Both DNAN and NTO were readily biotransformed under anaerobic conditions. Anaerobic degradation of DNAN occurred with half-lives between about 2 to 4 days. These soils had rather high OC.

A study by the Environmental Analytical Chemistry and Applied Ecotoxicology Groups (2012) found that soil microbes readily transformed DNAN in aerobic microcosms supplemented with nitrogen $\left(\mathrm{NH}_{4} \mathrm{Cl}\right)$ and carbon sources (glucose and succinate). DNAN disappeared at the rate of $1.7 \pm 0.2$ nmol h-1 g-1 and was completely removed in 8 days. DNAN only slowly disappeared in unamended microcosms with the loss of $0.58 \mu$ mols from initial concentration of $4 \mu \mathrm{mols}$ after 35 days, indicating a half-life of about 4.4 months or 0.37 year. This suggests that DNAN may persist longer under natural conditions.

Perreault et al. (2012a) reported the aerobic biotransformation of DNAN in artificially contaminated soil microcosms. DNAN was completely transformed in 8 days in soil slurries supplemented with carbon and nitrogen sources. DNAN was completely transformed in 34 days in slurries supplemented with carbon alone and persisted indefinitely in unamended micro- 
cosms. However, the persistent data does show a slight decrease in DNAN over 35 days from 4 to 3.5 micromole, which translates into a half-life of 182 days, or about 0.5 year.

In conclusion, for aerobic, unamended, natural conditions, the half-life of DNAN in soil is expected to vary in the range of a week to 2.2 years. The best estimate of expected half-life in soil is about 0.5 years. Half-lives are expected to vary with characteristics of the soil, but there is not presently enough information to specify any such relationships. Half-lives of DNAN in surface water are expected to be very short (on the order of a day) due to photooxidation, but depending on the environmental conditions, such as stream shading, water column light attenuation, and water depth, halflives in surface water could be longer.

\subsubsection{NTO}

Krzmarzick et al. (2015) were able to readily reduce NTO anaerobically in microcosms using inoculated microbial communities from seven different soils. However, NTO was nonbiodegradable in aerobic microcosms with all seven soil-inoculated communities. These results are similar to those for $\mathrm{RDX}$, where RDX is degraded under anaerobic conditions but degrades little for aerobic conditions. As with DNAN, microbial enrichment techniques have been used to biodegrade NTO rather rapidly for aerobic conditions. For example, Richard and Weidhaas (2014a) showed simultaneous aerobic degradation within four days for IM components DNAN, NTO, and NQ in the explosive formulation IMX101 using soil enrichment cultures involving sludge, soil, and compost.

Data from Dontsova et al. (2014b) showed some correlation for NTO decay rate in soil versus soil $\mathrm{OC}$, with rates that vary from 0.001 to 0.023 per hour, or half-life of 28.9 to 1.25 days. Their conclusions stated that NTO half-lives varied between 1.3 and 72 days, where decay rate increases with soil OC.

Field et al. (2014) stated that neither DNAN nor NTO were significantly degraded in any soil under aerobic conditions. However, both DNAN and NTO were readily biotransformed under anaerobic conditions. NTO was readily converted to 3 -amino-1, 2, 4-triazol-5 one (ATO), and ATO was not transformed further in anaerobic conditions. Rapid biodegradation of ATO in domed soils under aerobic conditions was confirmed by release of ammonium and mineralization of ATO carbon to $\mathrm{CO}_{2}$. 
The Environmental Analytical Chemistry and Applied Ecotoxicology Groups (2012) reported that NTO was removed slowly (25\% NTO removed after 28 days) in aerobic microcosms supplemented with glucose and succinate only. However, NTO persisted in unamended aerobic and anaerobic microcosms.

Dontsova et al. (2014a) found very rapid phototransformation rates of NTO, similar to DNAN, with half-lives of less than a day. Thus, NTO is expected to disappear fairly rapidly in surface water.

Based upon the above studies, it is concluded that NTO does not degrade or degrades very slowly in unamended, aerobic soils. It is difficult to set a range and recommended values for half-life of NTO in soil, but existing results suggest that NTO should degrade more slowly than DNAN and possibly NQ. For this study, a range of NTO half-lives in soil of 1 to 10 years is used with a mean, or recommended, value of 3 years. NTO halflives are expected to vary with characteristics of the soil, but there is not presently enough information to specify any such relationships. Half-lives of NTO in surface water are expected to be very short (on the order of a day) due to phototransformation, but depending on the environmental conditions, such as stream shading, water column light attenuation, and water depth, half-lives in surface water could be longer.

\subsubsection{NQ}

Haag et al. (1990) showed that nitroguanidine undergoes base-catalyzed hydrolysis for conditions of $25^{\circ} \mathrm{C}$ and a pH of 12 , but they also concluded that hydrolysis at environmental conditions $\left(25^{\circ} \mathrm{C}, \mathrm{pH}\right.$ less than 9) was slow, with half-lives greater than 100 days. Their data indicated that for a $\mathrm{pH}$ of 7 , hydrolysis half-life was 1.1 years. They concluded that NQ degrades very slowly in unamended, aerobic soils, but anaerobic conditions can increase NQ degradation. Haag et al. (1990) stated that the environmental fate of NQ in surface waters is dominated by photolysis with surface half-lives on the order of a day.

NQ in soil columns was studied by Kaplan and Kaplan (1985) with continuous water flow through the columns. NQ could be degraded if sufficient carbon (glucose) was added with the NQ in the influent water. The primary product was ammonia. NQ did not degrade without sufficient carbon. Their preliminary work also showed that NQ will degrade under anaerobic 
conditions. Williams et al. (1989) also concluded that carbon must be added to cause degradation of NQ.

Perreault et al. (2012b) reported that NQ was efficiently degraded in aerobic soil microcosms when a carbon source of glucose and succinate was added. However, NQ persisted in unamended microcosms or under anaerobic conditions. An aerobic NQ-degrading bacterium, Variovorax strain $\mathrm{VC} 1$, was isolated from soil microcosms containing NQ as the sole nitrogen source. NQ degradation was inhibited in the presence of a more favorable source of nitrogen.

Richard and Weidhaas (2014a) studied simultaneous aerobic degradation of the IMX-101 formulation constituents DNAN, NTO, and NQ, and degradation products were examined. Degradation products over four days of incubation included nitrourea; 1,2-dihydro-3H-1,2,4-triazol-3-one; and 2,4-dinitrophenol. The enrichment culture maximum specific growth rate of $0.12 \mathrm{~h}-1$ and half saturation constant of $288 \mathrm{mg} \mathrm{L}-1$ during degradation of IMX-101 as a sole nitrogen source suggest that enrichment culture growth kinetics may closely relate to those of other explosive and nitroaromatic compounds. All of DNAN and most of the NTO were aerobically degraded after nine days when soil was amended with carbon. The order of degradation was DNAN, NQ, and NTO. These EC are suspected to serve as a nitrogen source for microbial growth. However, DNAN was found to serve as either a carbon or nitrogen source. In another paper by Richard and Weidhaas (2014b), they reported results of degradation of IMX-101 components in soil. Control plots, where no plants and no enrichment culture were added, were sampled on days 0 and 225 and showed a decline of 83,83 , and $95 \%$ in DNAN, NTO, and NQ concentrations, respectively.

Mulherin et al. (2005) studied the stability of NQ in three moist, unsaturated soils under laboratory conditions. This study yielded a range of 15 to 56 days in the half-life decay estimates for NQ, depending on soil organic carbon, where half-life decreased with increasing soil organic carbon.

The above-cited studies indicate a wide variation of NQ half-lives in soil, ranging from days to possibly years. There is evidence that long half-lives can prevail for unamended, natural soils with near neutral $\mathrm{pH}$. Given these results, a range of NQ half-life in soil from 0.3 to 3 years with an average of 1 year was used for this study. Half-lives of NTO in surface water are expected to be very short (on the order of a day) due to photolysis, but de- 
pending on the environmental conditions, such as stream shading, water column light attenuation, and water depth, half-lives in surface water could be longer than a day.

\subsubsection{Summary}

The mean and range of recommended EC half-lives for use in this study are summarized in Table 5 .

Table 5. Recommended half-lives (years) of EC.

\begin{tabular}{|l|c|c|c|c|}
\hline \multicolumn{1}{|c|}{ EC } & $\begin{array}{c}\text { Mean half-life } \\
\text { in soil, yr }\end{array}$ & $\begin{array}{c}\text { Maximum } \\
\text { half-life in } \\
\text { soil, yr }\end{array}$ & $\begin{array}{c}\text { Minimum } \\
\text { half-life } \\
\text { in soil, yr }\end{array}$ & $\begin{array}{c}\text { Half-life } \\
\text { in } \\
\text { surface } \\
\text { water, } \\
\text { day }\end{array}$ \\
\hline DNAN & 0.5 & 2.2 & .02 & 1 \\
\hline NTO & 3 & 10 & 1 & 1 \\
\hline NQ & 1 & 3 & .3 & 1 \\
\hline
\end{tabular}




\section{Demo Area 2, MMR, Application}

\subsection{Background for model inputs}

This chapter presents the results of TREECS ${ }^{\mathrm{TM}}$ application to Demo Area 2 of MMR to assess the fate of the three EC in groundwater as affected by uncertain inputs for soil - water partitioning and half-life. The site description and model inputs for this study site were described previously (Dortch et al. 2007, Dortch 2012, Dortch 2015, and Dortch et al. 2017) so are not repeated here. However, basic information and key features of the model inputs regarding this application are described below to provide the background required for discussing model results.

Three modeling components of TREECS ${ }^{\mathrm{TM}}$ were used, including the Tier 2 soil model, the Multimedia Environmental Pollutant Assessment System (MEPAS) vadose zone model, and the MEPAS aquifer model. The option for average annual hydrology, rather than daily varying hydrology, was used in the soil model for this application due to the slow progression of groundwater transport that can take decades to be realized. A constant EC residue loading rate of 1,500 grams per year was applied for 10 years. This loading rate is the same as the HE RDX loading rate used in the previous applications to this site, which was estimated based on the types of demolition detonation charges used (Dortch 2007).

The model was run for 100 years using the adaptive time-step feature and minimum time step of 0.001 year. Zero initial soil contamination of EC was assumed. Surface soil runoff was assumed to be zero for the highly permeable soils; thus, all precipitation resulted in evapotranspiration and infiltration into the soil layer. The solid and adsorbed phase EC were assumed to be nondegradable (i.e., a high value of $1 \mathrm{E} 20$ years was used for half-life). Soil properties for silty loam and sand were used for surface soil and vadose/aquifer, respectively. Chemical-specific property inputs of the EC are presented in Table 1 and Table 2. The mean and range of recommended EC soil $K_{d}$ values are presented in Table 3. The mean and range of recommended EC half-lives are presented in Table 5.

The initial particle size of solid phase EC residue was set to $2791 \mu \mathrm{m}$ (microns) using the approach recommended by Dortch et al. (2017) that was based on the modeling of IMX-101 fate laboratory studies. This approach 
computes the mass-weighted average particle size. The mass-weighted averaged size was computed using the percent by mass of each constituent in IMX-101 and the representative particle size of each constituent, resulting in the input particle size of $2791 \mu \mathrm{m}$. This particle diameter was used as the input value for each of the three EC. The representa-tive particle size of $6000 \mu \mathrm{m}$ was used for DNAN when calculating the mass-weighted size. DNAN is the molten-cast matrix within which the smaller crystals reside (i.e., NTO and NQ for IMX-101). Thus, the particle size of DNAN was assumed to be the same as that estimated for RDX, which is the single HE component within the explosive formulation $\mathrm{C}_{4}$ used at Demo Area 2.

The well location for monitoring model output for groundwater concentration was set to the location of monitoring well 161 (MW161) at Demo Area 2 , which is one of the wells where $\mathrm{RDX}$ concentrations were measured in the field.

\subsection{Baseline results}

TREECS ${ }^{\mathrm{TM}}$ was applied using the inputs discussed in the previous section to establish baseline results for each EC. The recommended mean soil $K_{d}$ values and mean half-lives (HL) in surface and subsurface soil were used for the baseline application. $\mathrm{RDX}$ was also included in the baseline results for comparing the EC. The inputs for RDX were the same as those of the validation application presented by Dortch et al. (2017). The HL in waterdissolved phase in soil, vadose, and aquifer was set to 100 years for the modeling of RDX.

The aquifer well concentrations in parts per billion (ppb), or micrograms per liter $(\mu \mathrm{g} / \mathrm{L})$, for the three EC and RDX are plotted versus time as shown in Figure 1. The well concentrations of the three EC are much lower (far below any reasonable detection) than that of RDX. The reason for this is due to the slow degradation rate (relatively high HL) of RDX, which was based on previous validation modeling (Dortch et al. 2007, Dortch 2012, Dortch 2015, and Dortch et al. 2017). The three EC are almost totally degraded within the vadose zone due to their much greater degradation rates (i.e., smaller HL values) and the long transit time in that medium. Also, the three EC arrive at the receptor well later than RDX due to their higher $K_{d}$ values. 
Figure 1. Computed aquifer concentration of EC compared with RDX down-gradient of Demo Area 2, MMR, for baseline conditions.

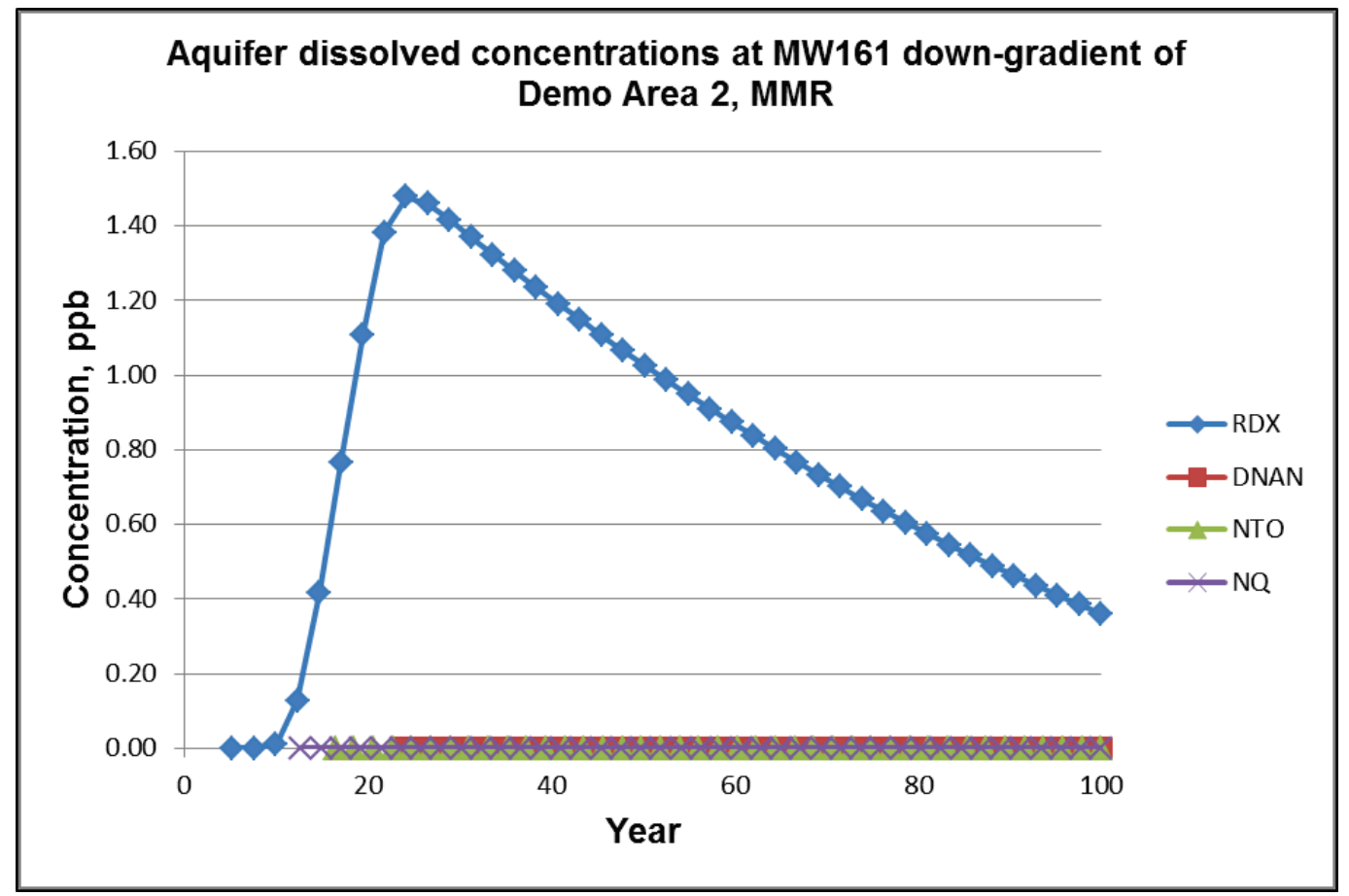

Given the above baseline results, the decision was made to apply the same HL values for each EC as used for RDX; i.e., 100 years for dissolved phase in all media, so that the fate of the EC relative to RDX could be better evaluated. The results of assuming an HL of 100 years in soil and groundwater for each EC are presented in Figure 2. Although the well peak concentrations of NTO and NQ occur later than that of RDX, these peak concentrations are greater than that of RDX due to the faster dissolution rate associated with the much higher water solubility of NTO and NQ. Although the dissolution rate of DNAN is a little faster than that of RDX, its higher soil partitioning causes substantial delay and attenuation of peak aquifer concentration, resulting in a peak concentration that is similar to that of RDX for the same degradation rate, or HL. Given the great uncertainty regarding the EC degradation rates and the evidence that EC degradation can be quite slow in natural, unamended, aerobic groundwater, the results in Figure 2 may not be unrealistic.

The next application consisted of baseline conditions with two exceptions, soil constituent loadings and HL values. For this application, the constituent loading rates to soil were held constant at $1500 \mathrm{~g} / \mathrm{yr}$ for 200 years, and HL values for all constituents were set to 1E2O years in all media, or essentially no degradation. The application was run for 200 years. The results of 
this application are not shown, but they showed that RDX and all three EC eventually reached a steady-state aquifer well concentration of $9 \mathrm{ppb}$, but some constituents took longer than others to reach steady state. Both NTO and NQ reached steady state much faster than DNAN and RDX due to their high solubility (and dissolution rate) and low $K_{d}$ values. Steady state was reached in about 55 and 60 years for NQ and NTO, respectively. DNAN required about 150 years to reach steady state, while RDX had not quite reached steady state after 200 years due to its much lower solubility.

Figure 2. Computed aquifer concentration of EC compared with RDX down-gradient of Demo Area 2, MMR, for 100-year HL for all constituents in all media.

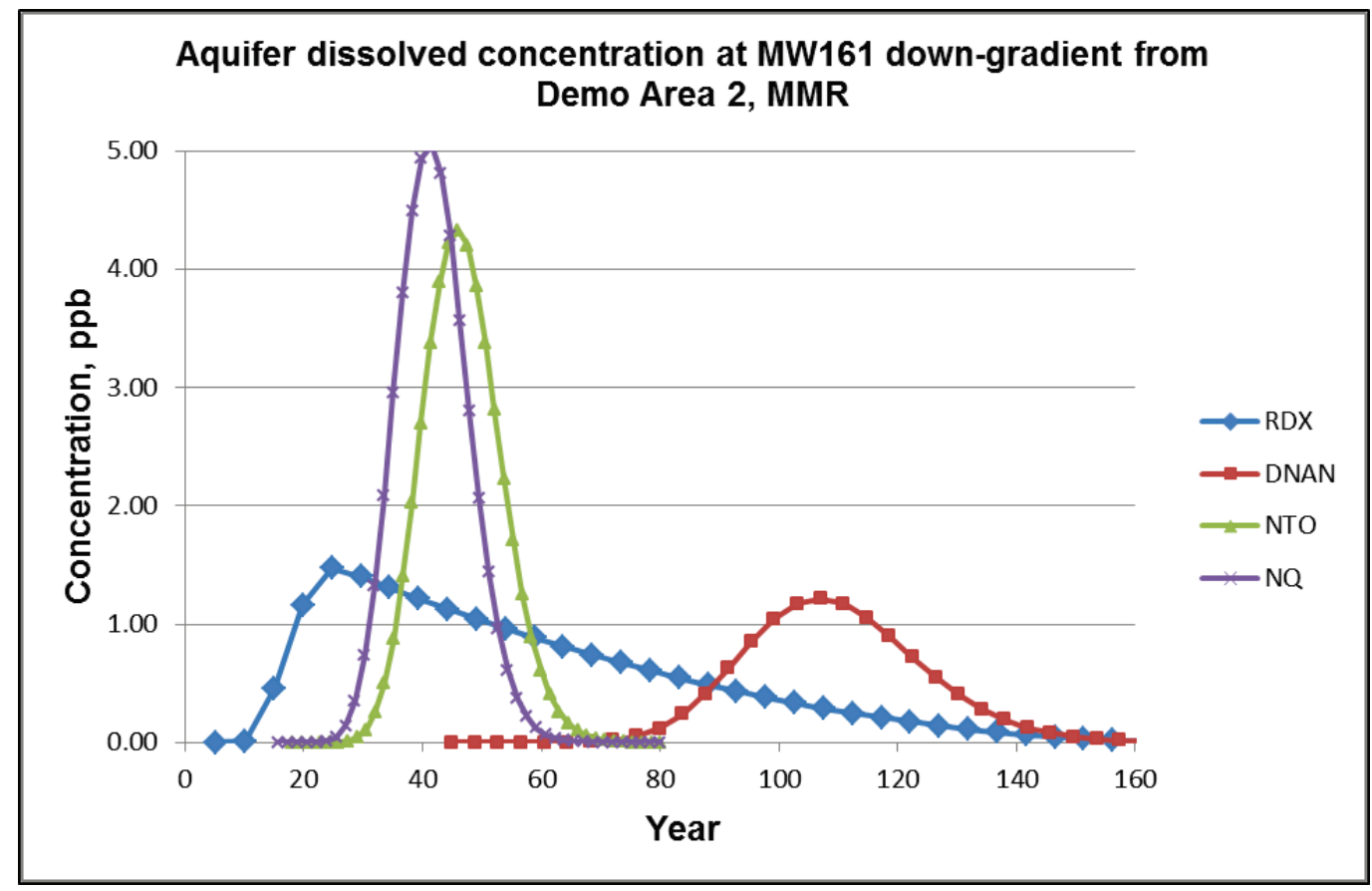

\subsection{Tracer study}

A simulation of a miscible, nonreactive, nonadsorbing tracer was conducted to determine the residence time in surface soil and transit time through the vadose zone and aquifer to the receiving well. This simulation was conducted by selecting one of the EC, which was DNAN in this case, and setting its $K_{d}$ values to nearly zero; i.e., 1E20, and its HL values to essentially infinity (1E20 years) for all media. The constituent was set to miscible in the soil model inputs, which means that its solid phase dissolves instantly. The constituent, or tracer, loading rate to soil was set to a constant value for 100 years, and the simulation was run for 200 years. Tracer concentrations were plotted versus time for soil, vadose zone, and aquifer receptor well (MW161). 
The concentration plot for soil revealed that the tracer residence time in soil is approximately three months. The other two plots showed that the transit time through the vadose zone and aquifer from the vadose zone entry to receptor well are approximately 14 years and 2 months, respectively. The exact transit time through the aquifer to the well was difficult to determine due to the coarseness of model output relative to the length of the simulation. However, with a Darcy velocity of $100 \mathrm{~cm} /$ day, an effective porosity of 0.3 , and well distance of $198 \mathrm{~m}$ from the source, the travel time should be two months from vadose entry to receptor well.

The tracer application revealed that the transit time through the vadose zone is by far the most important aspect with regard to constituent degradation and fate for this study site. However, not all groundwater sites will have this characteristic. For many sites, transit time and degradation within the aquifer will be more important than for the vadose zone. This site has a thick vadose, or water-unsaturated zone, and a relatively short aquifer travel distance from vadose entry to receptor well. For many sites, the opposite can be the case; i.e., the vadose zone thickness can be small relative to the aquifer transit distance to the receptor well.

Residence and transit times for specific EC with adsorption are quite different from that associated with a nonabsorbing tracer. Each of the three EC were next tested individually to evaluate their residence and transit times and sensitivity to uncertain $K_{d}$ and HL values.

\subsection{DNAN sensitivity}

\subsubsection{Residence and transit times}

A simulation of DNAN was conducted to evaluate its residence time in surface soil and transit times through the vadose zone and aquifer from vadose entry to receptor well. This simulation was conducted in the same manner as described above for a general tracer. Thus, DNAN was treated as a miscible constituent with a constant soil loading rate for 100 years and no degradation in any media. The exception was that the $K_{d}$ values were set to the recommended mean values for DNAN, or $1.75 \mathrm{~L} / \mathrm{kg}$ for soil and $1.07 \mathrm{~L} / \mathrm{kg}$ for vadose and aquifer (see Table 3 ).

The results of this simulation showed that the residence time in soil is about one year, and the transit time through the vadose zone and from vadose entry into the aquifer to the receiving well are about 101 and 1 years, 
respectively. These times are much greater than those associated with the nonabsorbing tracer. Adsorption has the effect of extending residence and transit times, which is referred to as transport retardation. Given the much longer transit time through the vadose zone, it is easy to see why the degradation rate for the vadose zone is so sensitive and important for this study site. The results of this application also reinforce the importance of the soil partitioning due to its impact on the effectiveness of degradation. For example, higher soil partitioning causes extended transit time, which provides more time for degradation, thus increasing the importance of accurately estimating the degradation rate.

\subsubsection{Half-lives}

The sensitivity of aquifer concentrations to half-life of DNAN in each medium was evaluated. This sensitivity analysis was conducted by varying the HL in one medium at a time while setting the HL to 100 years for the other two media and then comparing computed aquifer peak well concentration to the peak computed with HL set to 100 years for all three media (see Figure 2). All $K_{d}$ values were set to baseline values for these model runs (see recommended mean values in Table 3).

Using the maximum recommended DNAN HL of 2.2 years in soil (see Table 5) and 100 years below ground in vadose and aquifer only slightly affected the aquifer well concentration, reducing the peak concentration from 1.22 ppb for 100-year half-life in all media to $1.19 \mathrm{ppb}$, or a $2.5 \%$ reduction. Using the minimum recommended half-life in soil of 0.02 years and 100 years below ground resulted in reducing well peak concentration by almost a factor 4 to $0.32 \mathrm{ppb}$, or a $74 \%$ reduction from results with a 100-year half-life in all media.

With the maximum recommended DNAN HL of 2.2 years in aquifer (see Table 5) and 100 years in soil and vadose zone, the aquifer peak well concentration was reduced from $1.22 \mathrm{ppb}$ for 100 -year half-life in all media to $0.86 \mathrm{ppb}$, or a $30 \%$ reduction. Using the minimum recommended half-life in aquifer of 0.02 years and 100 years for soil and vadose zone resulted in essentially zero concentration in the aquifer. This result is due to the rather long transit time of DNAN in the aquifer to the receptor well, allowing time for complete degradation with the short HL value.

Using a half-life of 2.2 years in the vadose zone and 100 years in the other two media, resulted in a peak well concentration of 3.6E-14 ppb, or essen- 
tially zero concentration in the aquifer. The total loss of DNAN in the vadose zone is due to the much longer residence time in the vadose zone and the low HL used for DNAN.

Aquifer concentrations of DNAN are moderately sensitive to HL in surface soil, but are strongly affected by HL in vadose and aquifer for this site. These results are due to the long transit times of DNAN through the vadose zone and in the aquifer. The transit times are extended for DNAN relative to a nonadsorbing tracer due to soil partitioning.

\subsubsection{Soil partitioning}

The sensitivity of aquifer concentrations to DNAN $K_{d}$ values in each medium was evaluated. This sensitivity analysis was conducted by varying $K_{d}$ in one medium at a time while setting the $K_{d}$ values to the recommended means for the other two media and then comparing computed aquifer peak well concentration to the peak computed with recommended mean $K_{d}$ values for all three media (see Figure 2). All HL values were set to 100 years for these model runs.

Using the recommended maximum DNAN $K_{d}$ value in surface soil of 2.73 $\mathrm{L} / \mathrm{kg}$ (see Table 3) resulted in an aquifer peak well concentration of 1.21 ppb compared to $1.22 \mathrm{ppb}$ for the recommended mean DNAN $K_{d}$ value in surface soil of $1.75 \mathrm{~L} / \mathrm{kg}$. Using the recommended minimum DNAN $K_{d}$ value in surface soil of $0.78 \mathrm{~L} / \mathrm{kg}$ (see Table 3) resulted in an aquifer peak well concentration of $1.28 \mathrm{ppb}$ compared to $1.22 \mathrm{ppb}$ for the recommended mean DNAN $K_{d}$ value. Thus, aquifer concentrations of DNAN for this site are fairly insensitive to surface soil DNAN $K_{d}$ values. However, it is recognized that the sensitivity to surface soil $K_{d}$ values would increase for lower HL in soil.

The maximum and minimum DNAN $K_{d}$ values were applied for the aquifer with all other $K_{d}$ values for the other two media set to recommended mean values (see Table 3). These simulations showed that aquifer concentrations of DNAN were quite close (about $0.01 \mathrm{ppb}$ difference) to those computed using the recommended mean value. Thus, aquifer concentrations of DNAN for this site are practically insensitive to aquifer DNAN $K_{d}$ values.

Based on the above transit time analysis, aquifer DNAN concentrations should be far more sensitive to the $K_{d}$ value for the vadose zone than for soil and aquifer. Using the maximum recommended value for DNAN va- 
dose $K_{d}$ of $1.68 \mathrm{~L} / \mathrm{kg}$, the peak well concentration for DNAN was $0.58 \mathrm{ppb}$ (52\% decrease from $1.22 \mathrm{ppb}$ ) and occurred after 154 years rather than 107 years using $K_{d}$ of $1.07 \mathrm{~L} / \mathrm{kg}$. Using the minimum recommended $K_{d}$ value of 0.48 for the vadose zone, a peak well concentration for DNAN of $3.07 \mathrm{ppb}$ (152\% increase from $1.22 \mathrm{ppb}$ ) was computed after 58 years. The percent of changes are disproportional due to the increased effect of degradation for the longer transit time associated with the higher $K_{d}$ value. The HL for all media was set to 100 years. It is concluded that aquifer DNAN concentrations are moderately to highly sensitive to $K_{d}$ values in the vadose zone for this site. Of course, the sensitivity of DNAN $K_{d}$ value in the vadose zone depends on DNAN HL in the vadose zone. Aquifer concentration dependence on DNAN $K_{d}$ value in the vadose zone is unimportant when applying the recommended DNAN HL values shown in Table 5 that vary between 0.02 and 2.2 years. Aquifer concentrations are essentially zero for these low HL values regardless of the DNAN $K_{d}$ value in the vadose zone.

\subsubsection{Conclusions}

Aquifer DNAN concentrations for this site are practically insensitive to $K_{d}$ values in soil and aquifer, but are quite sensitive to $K_{d}$ values in the vadose zone. The greater the $K_{d}$ value in a medium, the greater the effect of HL in that medium on constituent degradation, thus increasing the need for more accurate estimates of HL for that medium. Assuming a very long HL, aquifer peak concentrations vary with vadose zone $K_{d}$ due to the fact that the soil DNAN loading imposed at this site extended for a relatively brief, finite period of time (10 years). Had the loadings been steady state, steadystate aquifer concentrations would eventually have been reached, and for a very long HL, $K_{d}$ values would have had little effect on the steady-state concentration but would affect the time to reach steady state. Aquifer concentrations are highly dependent on HL in the vadose zone due to the much longer transit time in that medium for this study site. Aquifer DNAN concentrations are dependent on HL in the aquifer, but less so than for vadose zone. Aquifer concentrations of DNAN are moderately affected by HL in soil if there is little or no degradation in the vadose zone and aquifer. For example, reducing HL in soil from 100 to 0.02 years with a 100year HL for vadose and aquifer, reduced peak well concentration by a factor of about 4 . 


\subsection{NTO sensitivity}

\subsubsection{Residence and transit times}

A simulation of NTO was conducted to evaluate its residence time in surface soil and transit times through the vadose zone and aquifer from vadose entry to receptor well. This simulation was conducted in the same manner as described above for a general tracer and DNAN. Thus, NTO was treated as a miscible constituent with a constant soil loading rate for 100 years and no degradation in any media. The exception was that the $K_{d}$ values were set to the recommended mean values for NTO, or $0.52 \mathrm{~L} / \mathrm{kg}$ for soil and $0.36 \mathrm{~L} / \mathrm{kg}$ for vadose and aquifer (Table 3 ).

The results of this simulation showed that the residence time in soil is about 10 months, and the transit time through the vadose zone and from vadose to the receiving well are about 41 years and 5 months, respectively. These times are greater than those associated with the nonabsorbing tracer since adsorption has the effect of extending residence and transit times, or transport retardation. The $K_{d}$ values for NTO are lower than those for DNAN, which causes faster transit than DNAN through each medium.

\subsubsection{Half-lives}

The sensitivity of aquifer concentrations to half-life of NTO in each medium was evaluated. This sensitivity analysis was conducted by varying the HL in one medium at a time while setting the HL to 100 years for the other two media and then comparing computed aquifer peak well concentration to the peak computed with HL set to 100 years for all three media (see Figure 2). All $K_{d}$ values were set to baseline values for these model runs (see recommended mean values in Table 3).

Using the maximum recommended NTO HL of 10 years in soil (see Table 5 ) and 100 years below ground in vadose and aquifer only slightly affected the aquifer well concentration, reducing the peak concentration from 4.29 ppb for 100-year half-life in all media to $4.14 \mathrm{ppb}$, or a $3.5 \%$ reduction. Using the minimum recommended NTO half-life in soil of 1.0 year and 100 years below ground resulted in reducing well peak concentration to $4.05 \mathrm{ppb}$, or a $5.6 \%$ reduction from results with a 100-year half-life in all media. Thus, aquifer concentration of NTO is weakly sensitive to NTO HL in soil for the range of recommended NTO HL values. 
With the maximum recommended NTO HL of 10 years in aquifer (see Table 5) and 100 years in soil and vadose zone, the aquifer peak well concentration was reduced from $4.29 \mathrm{ppb}$ for 100 -year half-life in all media to $4.16 \mathrm{ppb}$, or a reduction of $3 \%$. Using the minimum recommended halflife in aquifer of 1 year and 100 years for soil and vadose zone resulted in a peak well concentration for NTO of $3.08 \mathrm{ppb}$, or a $28 \%$ reduction compared with using an HL of 100 years in all three media. Aquifer NTO concentrations are mildly sensitive to the HL of NTO in the aquifer for the range of recommended NTO HL values.

Using an NTO HL of 10 years in the vadose zone and 100 years in the other two media resulted in a peak well concentration of $0.39 \mathrm{ppb}$, or a reduction of $91 \%$ compared to an HL of 100 years. Using a NTO HL of 1 year in the vadose zone resulted in essentially zero aquifer concentration of NTO. The much greater loss of NTO in the vadose zone is due to the longer transit time in the vadose zone coupled with a relatively low HL used for NTO.

Aquifer concentrations of NTO for this site are weakly sensitive to NTO HL in surface soil and mildly sensitive to NTO HL in aquifer, but are strongly affected by HL in the vadose zone. The high sensitivity to vadose zone HL is due to the relatively long vadose zone transit time coupled with the range of recommended HL values.

\subsubsection{Soil partitioning}

The sensitivity of aquifer concentrations to NTO $K_{d}$ values in each medium was evaluated. This sensitivity analysis was conducted by varying $K_{d}$ in one medium at a time while setting the $K_{d}$ values to the recommended means for the other two media and then comparing computed aquifer peak well concentration to the peak computed with recommended mean $K_{d}$ values for all three media (see Figure 2). All HL values were set to 100 years for these model runs.

Using the recommended maximum NTO $K_{d}$ value in surface soil of 0.91 $\mathrm{L} / \mathrm{kg}$ (see Table 3) resulted in an aquifer peak well concentration of 4.17 ppb compared to $4.29 \mathrm{ppb}$ for the recommended mean NTO $K_{d}$ value in surface soil of $0.52 \mathrm{~L} / \mathrm{kg}$, which is a reduction of $2.8 \%$. Using the recommended minimum NTO $K_{d}$ value in surface soil of $0.36 \mathrm{~L} / \mathrm{kg}$ (see Table 3) resulted in an aquifer peak well concentration of $4.47 \mathrm{ppb}$ compared to $4.29 \mathrm{ppb}$ for the recommended mean NTO $K_{d}$ value, or an increase of 4.2 
$\%$. Thus, aquifer concentrations of NTO for this site have a low sensitivity to surface soil NTO $K_{d}$ values. However, it is recognized that the sensitivity to surface soil $K_{d}$ values would increase for lower HL in soil.

The maximum and minimum NTO $K_{d}$ values were applied for the aquifer with all other $K_{d}$ values for the other two media set to recommended mean values (see Table 3). These simulations showed that aquifer concentrations of NTO were quite close (less than $0.01 \mathrm{ppb}$ difference) to those computed using the recommended mean $K_{d}$ value. Thus, aquifer concentrations of NTO for this site are practically insensitive to aquifer NTO $K_{d}$ values.

Using the maximum recommended value for NTO vadose $K_{d}$ of $0.64 \mathrm{~L} / \mathrm{kg}$, the peak well concentration for NTO was $2.51 \mathrm{ppb}$ ( $41 \%$ decrease from $4.29 \mathrm{ppb}$ ) and occurred after 68 years rather than 47 years using $K_{d}$ of $0.36 \mathrm{~L} / \mathrm{kg}$. Using the minimum recommended $K_{d}$ value of 0.25 for the vadose zone, a peak well concentration for NTO of $5.44 \mathrm{ppb}$ ( $27 \%$ increase from $4.29 \mathrm{ppb}$ ) was computed after 38 years. The percent of changes are disproportional due to the increased effect of degradation for the longer transit time associated with a higher $K_{d}$ value. The HL for all media was set to 100 years. It is concluded that aquifer NTO concentrations are moderately sensitive to $K_{d}$ values in the vadose zone for this site. The sensitivity of NTO $K_{d}$ value in the vadose zone depends on NTO HL in the vadose zone, where lower vadose HL increases sensitivity of vadose $K_{d}$ value.

\subsubsection{Conclusions}

Aquifer NTO concentrations for this site are practically insensitive to $K_{d}$ values in soil and aquifer, but are moderately sensitive to $K_{d}$ values in the vadose zone. However, assuming a very long HL, aquifer concentrations vary with vadose zone $K_{d}$ due to the fact that the soil NTO loading imposed at this site extended for a relatively brief finite period of time (10 years). Had the loadings been steady state, steady-state aquifer concentrations would eventually be reached, and for a very long HL, $K_{d}$ values would have had little effect on the steady-state concentration but would have affected the time required to reach steady state. Aquifer concentrations of NTO for this site are weakly sensitive to NTO HL in surface soil and mildly sensitive to NTO HL in aquifer, but are strongly affected by HL in the vadose zone. 


\subsection{NQ sensitivity}

\subsubsection{Residence and transit times}

A simulation of NQ was conducted to evaluate its residence time in surface soil and transit times through the vadose zone and aquifer from vadose entry to receptor well. This simulation was conducted in the same manner as described above for a general tracer, DNAN, and NTO. Thus, NQ was treated as a miscible constituent with a constant soil loading rate of 50 years and no degradation in any medium. The exception was that the $K_{d}$ values were set to the recommended mean values for NQ, or $0.3 \mathrm{~L} / \mathrm{kg}$ for all media (Table 3).

The results of this simulation showed that the residence time in soil is about 2 months, and the transit time through the vadose zone and from vadose to the receiving well are about 35 years and 4 months, respectively. NQ moves through each medium faster than DNAN and NTO due to the lower $K_{d}$ values of NQ.

\subsubsection{Half-lives}

The sensitivity of aquifer concentrations to half-life of NQ in each medium was evaluated. This sensitivity analysis was conducted by varying the HL in one medium at a time while setting the HL to 100 years for the other two media and then comparing computed aquifer peak well concentration to the peak computed with HL set to 100 years for all three media (see Figure 2). All $K_{d}$ values were set to baseline values for these model runs (see recommended mean values in Table 3).

Using the maximum recommended NQ HL of 3 years in soil (see Table 5) and 100 years below ground in vadose and aquifer only slightly affected the aquifer well concentration, reducing the peak concentration from 5.05 $\mathrm{ppb}$ for 100-year half-life in all media to $4.75 \mathrm{ppb}$, or $5.9 \%$ reduction. Using the minimum recommended NQ half-life in soil of 0.3 years and 100 years below ground resulted in reducing well peak concentration to 4.14 ppb, or $18 \%$ reduction from results with a 100-year half-life in all media. Thus, aquifer concentration of NQ is mildly sensitive to NQ HL in soil for the range of recommended NQ HL values.

With the maximum recommended NQ HL of 3 years in aquifer (see Table 5) and 100 years in soil and vadose zone, the aquifer peak well concentra- 
tion was reduced from $5.05 \mathrm{ppb}$ for 100 -year half-life in all media to 4.58 $\mathrm{ppb}$, or a reduction of $9.3 \%$. Using the minimum recommended half-life in aquifer of 0.3 year and 100 years for soil and vadose zone resulted in a peak well concentration for NQ of $1.9 \mathrm{ppb}$, or a $62 \%$ reduction compared with using an HL of 100 years in all three media. Aquifer NQ concentrations are moderately sensitive to the HL of NQ in the aquifer for the range of recommended NQ HL values.

Using a NQ HL of 3 years in the vadose zone and 100 years in the other two media resulted in essentially zero aquifer concentration of NQ. The much greater loss of NQ in the vadose zone is due to the longer transit time in the vadose zone coupled with a relatively low HL for NQ.

Aquifer concentrations of NQ for this site are weakly sensitive to NQ HL in surface soil and moderately sensitive to NQ HL in aquifer, but are strongly affected by HL in the vadose zone. The high sensitivity to vadose zone HL is due to the relatively long vadose zone transit time coupled with the range of recommended HL values.

\subsubsection{Soil partitioning}

The sensitivity of aquifer concentrations to NQ $K_{d}$ values in each medium was evaluated. This sensitivity analysis was conducted by varying $K_{d}$ in one medium at a time while setting the $K_{d}$ values to the recommended means for the other two media and then comparing computed aquifer peak well concentration to the peak computed with recommended mean $K_{d}$ values for all three media (see Figure 2). All HL values were set to 100 years for these model runs.

Using the recommended maximum and minimum NQ $K_{d}$ value in surface soil of 0.6 and $0.1 \mathrm{~L} / \mathrm{kg}$ (see Table 3) resulted in aquifer peak well concentrations very close (less than $0.02 \mathrm{ppb}$ ) to the value of $5.05 \mathrm{ppb}$, which was computed using the recommended mean NQ $K_{d}$ value in surface soil of 0.3 $\mathrm{L} / \mathrm{kg}$. Thus, aquifer concentrations of NQ for this site are practically insensitive to surface soil NQ $K_{d}$ values. However, it is recognized that the sensitivity to surface soil $K_{d}$ values would increase for lower HL in soil, where a value of 100 years was used for this analysis.

The maximum and minimum NQ $K_{d}$ values were applied for the aquifer with all other $K_{d}$ values for the other two media set to recommended mean values (see Table 3). These simulations showed that aquifer concentrations 
of NQ were quite close (less than $0.03 \mathrm{ppb}$ difference) to those computed using the recommended mean $K_{d}$ value. Thus, aquifer concentrations of NQ for this site are practically insensitive to aquifer NQ $K_{d}$ values.

Using the maximum recommended value for NQ vadose $K_{d}$ of $0.6 \mathrm{~L} / \mathrm{kg}$, the peak well concentration for NQ was $2.8 \mathrm{ppb}$ ( $45 \%$ decrease from 5.05 ppb) and occurred after 65 years rather than 41 years using $K_{d}$ of $0.3 \mathrm{~L} / \mathrm{kg}$. Using the minimum recommended $K_{d}$ value of 0.1 for the vadose zone, a peak well concentration for NQ of $7.49 \mathrm{ppb}$ (48\% increase from $5.05 \mathrm{ppb}$ ) was computed after 24 years. It is concluded that aquifer NQ concentrations are moderately sensitive to $K_{d}$ values in the vadose zone for this site. The sensitivity of NQ $K d$ value in the vadose zone depends on NQ HL in the vadose zone. However, the sensitivity of NQ vadose $K_{d}$ value is of little consequence for the NQ HL values shown in Table 5 that vary between .3 and 3 years since an HL of 3 years resulted in low NQ aquifer concentrations (0.15 ppb with an NQ vadose $K_{d}$ value of $0.1 \mathrm{~L} / \mathrm{kg}$ ).

\subsubsection{Conclusions}

Aquifer NQ concentrations for this site are practically insensitive to $K_{d}$ values in soil and aquifer, but are moderately sensitive to $K_{d}$ values in the vadose zone. However, assuming a very long HL, aquifer concentrations vary with vadose zone $K_{d}$ due to the fact that the soil NQ loading imposed at this site extended for a relatively brief finite period of time (10 years). Had the loadings been steady state, steady-state aquifer concentrations would eventually be reached, and for a very long HL, $K_{d}$ values would have little effect on the steady-state concentration but would affect the time to reach steady state. Aquifer concentrations of NQ for this site are weakly sensitive to NQ HL in surface soil and moderately sensitive to NQ HL in aquifer, but are strongly affected by HL in the vadose zone. The high sensitivity to vadose zone HL is due to the relatively long vadose zone transit time coupled with the range of recommended HL values.

\subsection{Summary}

It is important to know soil residence time and transit time through the vadose zone and aquifer to more fully understand why some model inputs are more important than others. The amount of constituent degradation in various media depends on the degradation rate (i.e., HL) in a medium and the time spent in that medium. The time spent in a medium is affected by the soil partitioning coefficient. The tracer simulation for this study site 
showed that the soil residence time and transit time through the aquifer (from vadose entry to receptor well) is only a few months, whereas the transit time through the vadose zone is approximately 14 years for a nonadsorbing tracer. With soil partitioning of the EC, the residence and transit times are extended; i.e., transport is retarded. The vadose zone is by far the most important medium for this site with regard to EC fate.

The sensitivity results obtained through the model applications for the three EC to Demo Area 2, MMR, are summarized in Table 6. It should be recognized that the high sensitivity of some inputs are related to the site characteristics. For example, this site has a much longer transit time through the vadose than through the aquifer, but the reverse can be the case for other sites.

Table 6. Sensitivity of aquifer EC concentrations to inputs for soil partitioning and degradation.

\begin{tabular}{||c||c|c|c||c|l|l||}
\hline EC & Soil HL & Aquifer HL & Vadose HL & Soil $K_{d}$ & Aquifer $K_{d}$ & Vadose $K_{d}$ \\
\hline \hline DNAN & Moderate & High & Very high & Low & Very low & $\begin{array}{c}\text { Moderate } \\
\text { to high }\end{array}$ \\
\hline NTO & Low & $\begin{array}{c}\text { Low to } \\
\text { moderate }\end{array}$ & $\begin{array}{c}\text { High to } \\
\text { very high }\end{array}$ & Low & Very low & Moderate \\
\hline NQ & $\begin{array}{r}\text { Low to } \\
\text { moderate }\end{array}$ & Moderate & Very High & Very low & Very low & Moderate \\
\hline
\end{tabular}

Examination of Table 6 reveals that model results are either highly or very highly sensitive to model input values for vadose zone HL. Model results range from low to moderate sensitivity to soil HL input values. Model results range from low to high sensitivity to aquifer HL input values. Model results are either very lowly or lowly sensitive to model input values for soil and aquifer $K_{d}$ values. Results are moderately to highly sensitive to vadose $K_{d}$ values. Therefore, it is concluded that estimation of HL, particularly for vadose zone and groundwater, is critically important for the accuracy of model predictions. Furthermore, accurate estimation of HL is considerably more important than accurate estimation of $K_{d}$. However, it is recognized that $K_{d}$ can affect the influence of HL in each medium, where high $K_{d}$ values cause HL to exert more influence on model results. 


\section{Artillery Impact Area (AIA), USMA, Application}

\subsection{Background for model inputs}

This chapter presents the results of application of TREECS ${ }^{\text {TM }}$ to the AIA at USMA to assess the fate of the three EC in surface water as affected by uncertain inputs for soil-water partitioning and half-life. The site description and model inputs for this study site were described previously (Dortch 2012 for overall USMA ranges and Dortch et al. 2017 for AIA application) so are not repeated here. However, basic information and key features of the model inputs regarding this application are described below to provide the background required for discussing model results.

Two modeling components of TREECS ${ }^{\mathrm{TM}}$ were used, which included the Tier 2 soil model and the Contaminant Model for Streams (CMS). The option for average annual hydrology, rather than daily varying hydrology, was used in the soil model for this application to facilitate long-term (century) application. A constant EC residue loading rate of 49.8 kilograms per year was applied for 100 years. This loading rate is the same as the HE RDX loading rate used in the previous applications to this site (Dortch et al. 2017); the rate was calculated with the TREECS ${ }^{\mathrm{TM}}$ impact zone MC residue calculator based on the numbers and types of munitions fired on these artillery ranges as described by Dortch et al. (2017).

The model was run for 100 years using the adaptive time step feature and minimum time step of 0.001 year. Zero initial soil contamination of EC was assumed. All of the soil infiltrating water and EC mass flux was assumed to be returned to surface flow via soil interflow due to bedrock that underlies surface soil, thus preventing percolation. Solid and adsorbed phase EC were assumed to be nondegradable; thus, a high value of $1 \mathrm{E} 20$ years was used in the soil model for half-life of solid-phase EC and EC adsorbed to soil, and a degradation rate of zero was used in CMS forEC adsorbed to stream benthic and suspended sediments. Soil properties for sandy loam were used for range impact zone surface soil. Chemicalspecific property inputs of the EC are presented in Table 1 and Table 2. The mean and range of recommended EC soil and sediment $K_{d}$ values are 
presented in Table 3 and Table 4, respectively. The mean and range of recommended EC half-lives are presented in Table 5.

The initial particle size of solid phase EC residue was set to $5,401 \mu \mathrm{m}$ using an approach recommended by Dortch et al. (2017), which was based on modeling of IMX-101 fate laboratory studies. This approach is described in the previous chapter. The only difference in the calculation of particle size here from the previous calculation for Demo Area 2 is that the representative size of RDX was 12,000 $\mu \mathrm{m}$ rather than 6,000 used for Demo Area 2. The RDX particle size was assumed to correspond to the DNAN particle size with the procedure. The particle diameter of $5,401 \mu \mathrm{m}$ was used as the input value for each of the three EC.

The target receptor location is Popolopen Brook, which receives drainage from the area of interest (AOI), or the AIA for the USMA artillery ranges. For the previous AIA application (Dortch et al. 2017), the target receptor location was set at $50 \mathrm{~m}$ downstream of the AIA influent into Popolopen Brook (the beginning of the modeled stream reach), which is the approximate location where stream samples were collected. Thus, this location was also used for the present application. However, a second target receptor location further downstream was also used to evaluate the importance of EC degradation within the stream. The second location was arbitrarily placed 5,000 $\mathrm{m}$ downstream from the beginning of the modeled stream reach. This much longer distance was chosen to provide ample travel time for degradation to have a perceivable effect. All other inputs pertaining to meteorology, soil conditions, hydrology, stream conditions, and hydraulics are provided by Dortch et al. (2017).

\subsection{Baseline results}

TREECS ${ }^{\mathrm{TM}}$ was applied using the inputs referenced and discussed in the previous section to establish baseline results for each EC. The recommended mean soil $K_{d}$ values and mean HL for surface soil, stream sediments, and surface water were used for the baseline application. RDX was also included in the baseline results for comparing the EC. The inputs for RDX were the same as those of the validation application presented by Dortch et al. (2017). The HL of RDX in AOI soil was set to 10 years, and zero degradation rate of RDX was used in the stream for the validation application. 
The stream total concentrations (particulate plus dissolved) in parts per billion (ppb), or micrograms per liter, for the three EC and RDX are plotted versus time for the upstream receptor target location as shown in Figure 3. The concentrations of the three EC are greater than that of RDX and reach a steady-state concentration much faster. Eventually RDX would also reach a steady-state concentration of about the same concentration as the EC if the model was run for a longer period of time. The much lower solubility and the larger initial particle size $(12,000 \mu \mathrm{m})$ of RDX are the reasons that it takes so much longer for RDX to reach steady state. Steadystate concentrations are the result of the constant AOI loading rate of EC and RDX. The differences in steady-state EC concentrations are caused by the differences in soil degradation rates or HL, where higher steady-state concentration corresponds with higher HL in soil.

Figure 3. Computed stream concentration of EC compared with RDX $50 \mathrm{~m}$ downstream of the AIA, USMA, for baseline conditions.

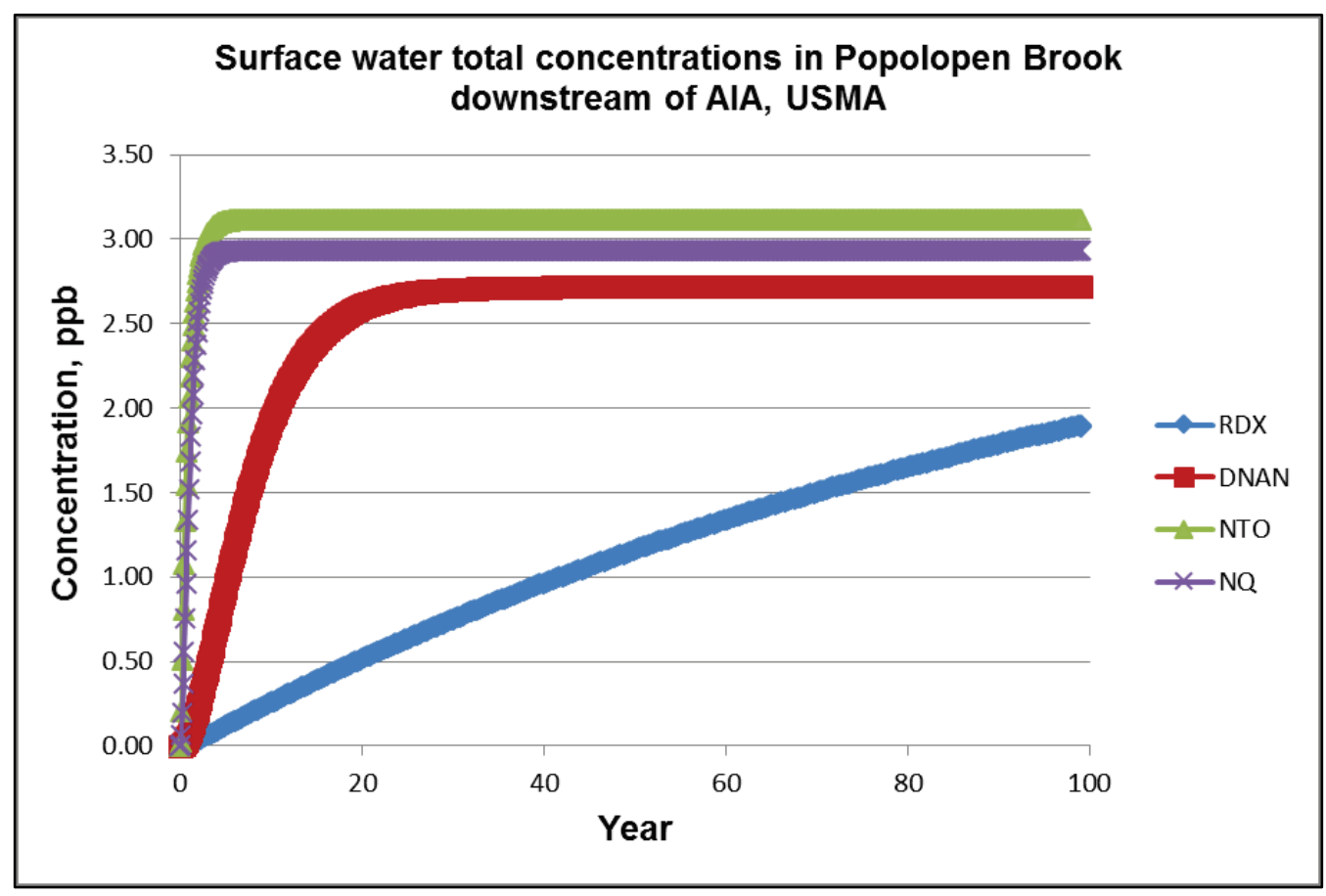

The application with baseline conditions was repeated, except that the receptor location was moved further downstream to 5,000 $\mathrm{m}$ downstream of the AIA. The results of this application are shown in Figure 4. With an HL of only one day for each EC, a substantial reduction in steady-state concentrations (compared with results in Figure 3) occurs over the longer stream reach where a longer travel time allows more degradation. The 
concentrations of RDX are essentially the same in Figure 3 and Figure 4 due to the assumption of no RDX degradation within the stream.

Figure 4. Computed stream concentration of EC compared with RDX 5000 m downstream of the AIA, USMA, for baseline conditions.

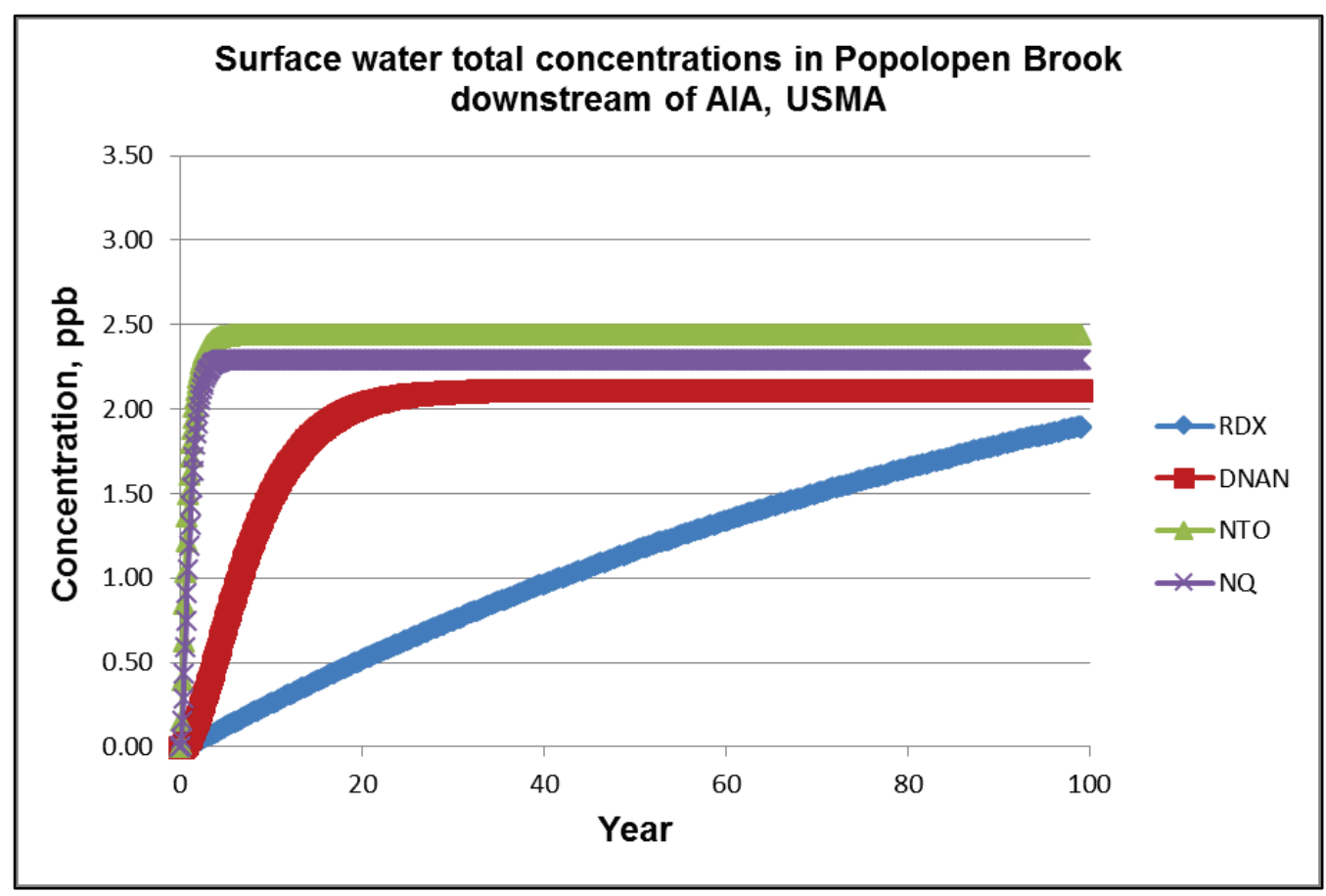

It is noted that the above baseline results are not totally realistic for actual field conditions. Stream concentrations of MC in the field have been found to be highly transient, varying from below detection to levels of several parts per billion. The higher concentrations occur during and immediately following significant rainfall events, and return to below detection as rainfall and runoff cease (Dortch et al. 2017). Thus, continuous, steady-state concentrations as shown above are not expected to occur in the field, but they serve the purposes of this study.

Tracer modeling was not performed for the AIA study area since travel time within the stream is relatively short and can be easily estimated. Short travel times in surface water result in less importance for accurately estimating surface water degradation rates or HL. The sensitivity of uncertain $K_{d}$ and HL values for this surface water system are discussed in the sections below. 


\subsection{DNAN sensitivity}

\subsubsection{Half-lives}

Given the highly transient nature of expected stream EC concentrations, the short travel times in streams, and the expected high photodegradation rates yielding HL on the order of one day, HL sensitivity was focused predominantly on soil HL values. All $K_{d}$ values were set to baseline values for these model runs (see recommended mean values in Table 3). All other inputs were the same as the baseline conditions with the exception of the length of simulation, which was shortened to 50 years since steady-state conditions are reached relatively quickly.

Monte Carlo uncertainty analysis was conducted by varying only the soil HL values and monitoring stream total EC concentrations at the upstream station (50 m downstream of the AIA). The mean soil HL for DNAN is 0.5 years (see Table 5) with lower and upper bounds of 0.02 and 2.2 years. A log normal distribution was assumed for the uncertainty analysis. The HL values for DNAN in Table 5 were converted to degradation rates as required by the Monte Carlo Sensitivity/Uncertainty (S/U) module by assuming a first order decay. Thus, the upper and lower bounds on degradation rate were set to 34.7 and 0.32 per year, respectively, within the S/U module UI. The log of the mean degradation rate was set to 0.14 per year using the HL of 0.5 year and was entered into the S/U UI. The difference in the logs of the upper and lower degradation rates was divided by 6 to estimate the standard deviation log of 0.34 per year that was input in the S/U UI. The S/U module was executed for 50 iterations, which was enough to reach consistent results with the Latin Hypercube sampling procedure.

The results of the above S/U application are plotted in Figure 5 for baseline results and upper and lower $95 \%$ confidence bands associated with uncertainty of soil DNAN HL. This figure shows that stream DNAN concentrations are substantially affected by soil HL. Two deterministic runs were executed with the soil HL set to the upper and lower bounds of 2.2 and 0.02 years. The resulting steady-state stream concentrations of DNAN were 3.08 and $0.57 \mathrm{ppb}$, respectively. The concentration of $3.08 \mathrm{ppb}$ is slightly greater than the upper confidence limit (UCL), and the concentration of $0.57 \mathrm{ppb}$ is about a fourth of the lower confidence limit (LCL). This rather large skewness of the confidence bands is due to using a log normal distribution with a mean HL of 0.5 years. 
Figure 5. Computed stream concentration of DNAN $50 \mathrm{~m}$ downstream of the AIA, USMA, with $95 \%$ confidence bounds for uncertainty of soil HL compared to baseline conditions.

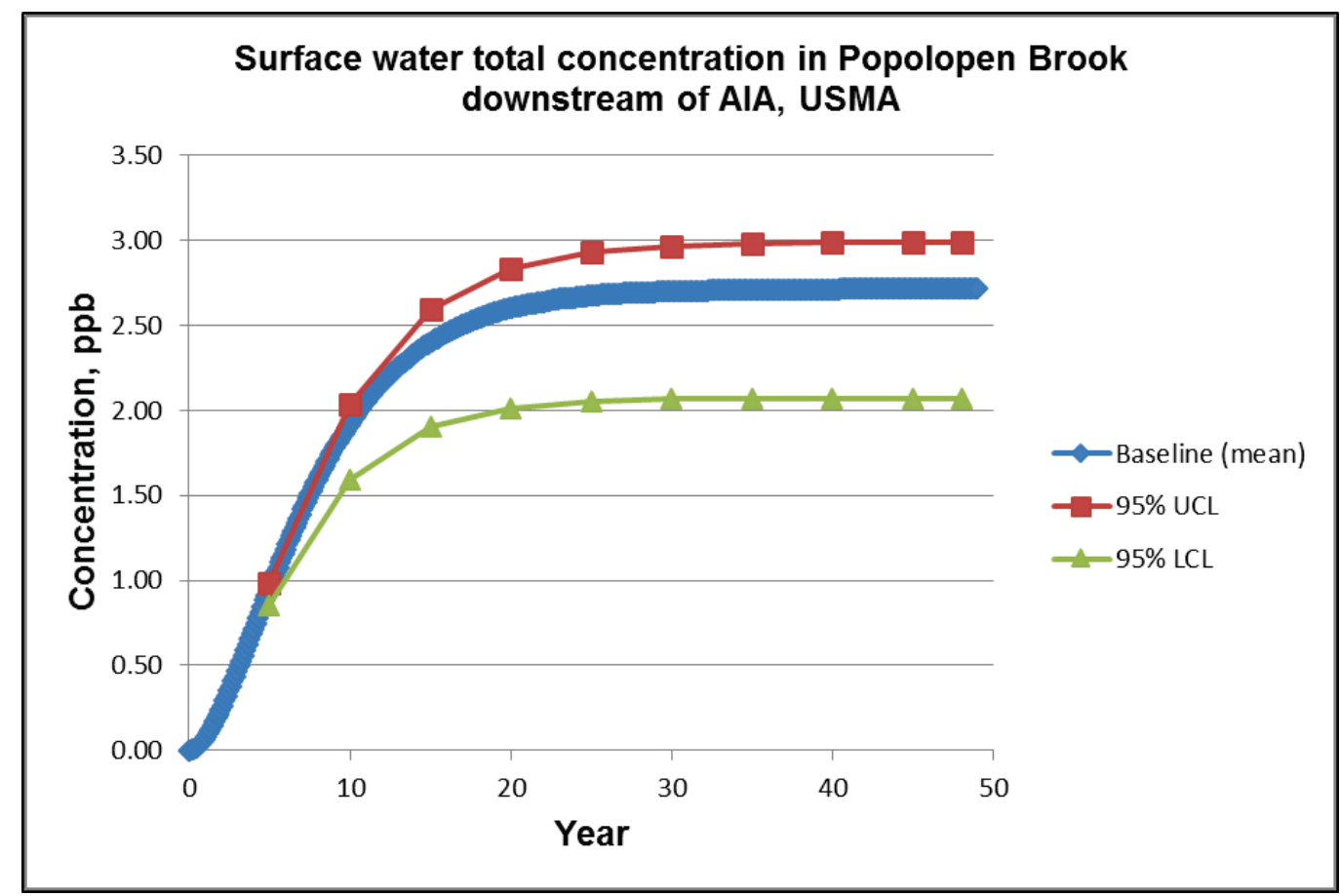

An application was performed to examine the sensitivity of the DNAN stream degradation rate for the second receptor location of 5,000 $\mathrm{m}$ downstream of the AIA. The stream degradation rate was set to zero for DNAN in this application. The resulting steady-state stream concentration of DNAN at the receptor location for this application was $2.71 \mathrm{ppb}$, which is about the same as the steady-state DNAN concentration at the upstream receptor location using a degradation rate of 1.0 per day (Figure 3). Figure 4 shows that the steady-state DNAN concentration at the downstream receptor location with a degradation rate of 1.0 per day is $2.12 \mathrm{ppb}$. Thus, the rather high degradation rate of 1.0 per day results in only a $0.59 \mathrm{ppb}$ decrease in stream concentration over 5,000 m compared with no degradation. It is concluded that stream concentrations of DNAN are more sensitive to soil HL than stream degradation rate. This higher sensitivity is due to the longer DNAN residence time in soil compared to travel time in the stream.

\subsubsection{Soil partitioning}

The sensitivity of stream DNAN concentrations to DNAN $K d$ values in soil was evaluated. Monte Carlo uncertainty analysis was conducted by varying only the soil DNAN $K_{d}$ values and monitoring stream total DNAN concen- 
trations at the upstream station (50 m downstream of the AIA). A normal distribution was assumed with a mean soil DNAN $K_{d}$ value of $2.98 \mathrm{~L} / \mathrm{kg}$ and lower and upper bounds of 1.33 and $4.66 \mathrm{~L} / \mathrm{kg}$ (see Table 3). The difference in the bound values divided by 6 resulted in a standard deviation of $0.56 \mathrm{~L} / \mathrm{kg}$. All four values were entered into the $\mathrm{S} / \mathrm{U} \mathrm{UI}$, and the $\mathrm{S} / \mathrm{U}$ module was run for 50 iterations.

The results of the above S/U application are plotted in Figure 6 for baseline results and upper and lower $95 \%$ confidence band associated with uncertainty of soil DNAN $K_{d}$ values. This figure shows that stream DNAN concentrations are hardly affected by soil $K_{d}$ values. Two deterministic runs were executed with the soil $K_{d}$ values set to the upper and lower bounds of 4.66 and $1.33 \mathrm{~L} / \mathrm{kg}$. The resulting steady-state stream concentrations of DNAN were 2.72 and $2.70 \mathrm{ppb}$, respectively, confirming that soil DNAN $K_{d}$ values have very little effect on stream concentrations of DNAN.

Figure 6. Computed stream concentration of DNAN $50 \mathrm{~m}$ downstream of the AIA, USMA, with $95 \%$ confidence bounds for uncertainty of soil $K_{d}$ values compared to baseline conditions.

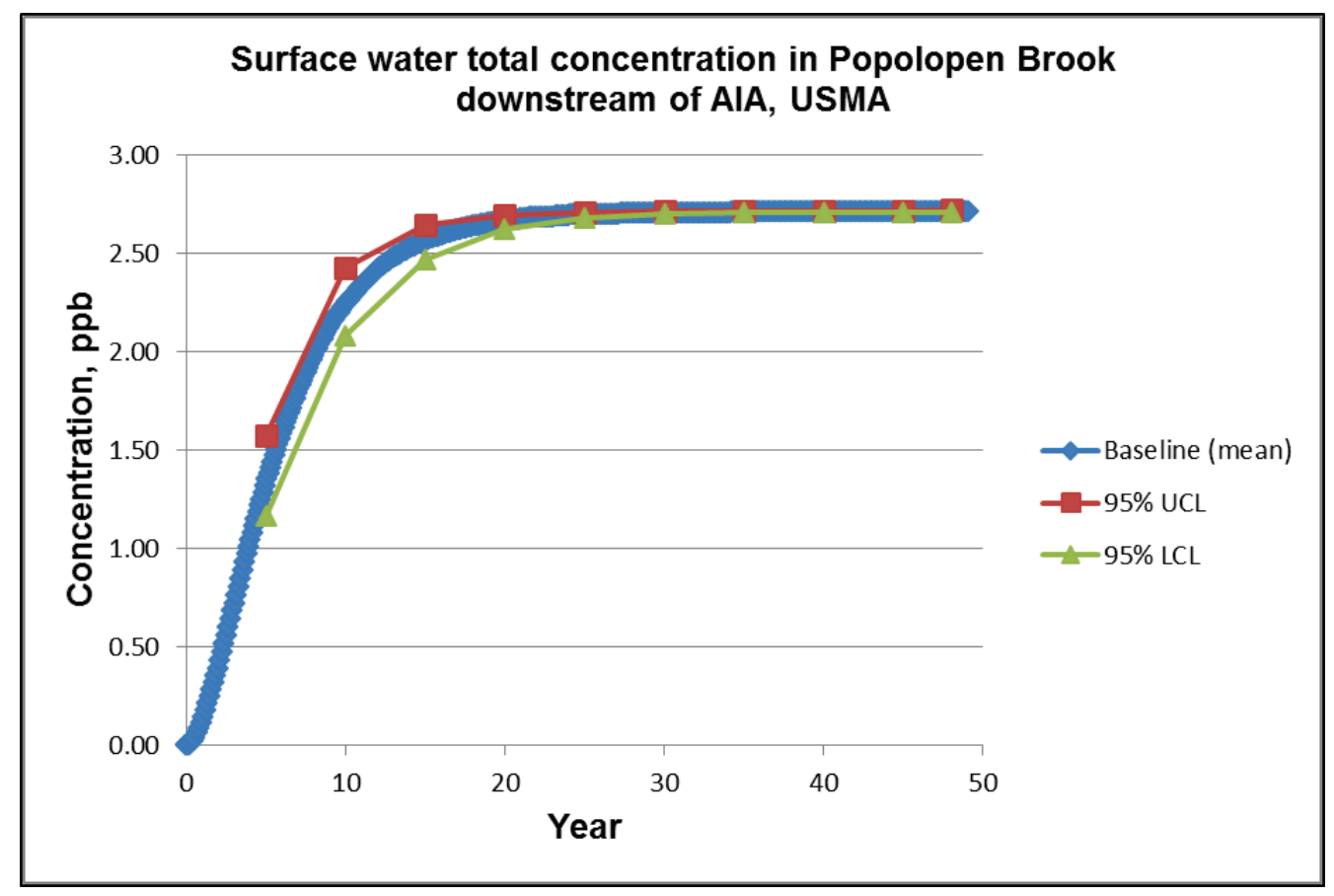

The sensitivity of DNAN $K_{d}$ values in water and sediments was evaluated by applying the baseline conditions with the maximum and minimum values for DNAN shown in Table 4 . The same sediment $K_{d}$ value was used for both benthic and suspended sediments. The computed steady-state stream 
DNAN concentrations were the same for both $K_{d}$ values, indicating insensitivity to varying stream DNAN $K_{d}$ values.

\subsubsection{Conclusions}

Surface water stream DNAN concentrations are moderately sensitive to soil HL and less sensitive to stream degradation rate. Stream DNAN concentrations for this site are insensitive to $K_{d}$ values in soil and stream.

\subsection{NTO sensitivity}

\subsubsection{Half-lives}

Monte Carlo uncertainty analysis was conducted by varying only the soil NTO HL values and monitoring stream total NTO concentrations at the upstream station (50 $\mathrm{m}$ downstream of the AIA). The mean soil HL for NTO is 3.0 years (see Table 5) with lower and upper bounds of 1.0 and 10.0 years. A log normal distribution was assumed for the uncertainty analysis. The HL values for NTO in Table 5 were converted to degradation rates as required by the Monte Carlo S/U module by assuming a first order decay. Thus, the upper and lower bounds on the degradation rate were set to 0.69 and 0.07 per year, respectively, within the S/U module UI. The log of the mean degradation rate was set to -0.636 per year using the HL of 3.0 years and was entered into the S/U UI. The difference in the logs of the upper and lower degradation rates was divided by six to estimate the standard deviation log of 0.167 per year that was input in the S/U UI. The $\mathrm{S} / \mathrm{U}$ module was executed for 50 iterations, which was enough to reach consistent results with the Latin Hypercube sampling procedure.

The results of the above S/U application are plotted in Figure 7 for baseline results and the upper and lower $95 \%$ confidence band associated with uncertainty of soil NTO HL. This figure shows that stream NTO concentrations are hardly affected by soil HL. Two deterministic runs were executed with the soil HL set to the upper and lower bounds of 10 and 1 years. The resulting steady-state stream concentrations of NTO were 3.19 and 2.93 $\mathrm{ppb}$, respectively, which confirmed the low sensitivity of stream NTO concentrations to soil NTO HL. Another S/U run was made assuming a normal distribution with the mean and bounds set the same as described above. The results of this run were nearly identical to those shown in Figure 7. NTO has a lower residence time in soil than DNAN due to its lower soil partitioning, thus rendering soil HL as less sensitive. 
Figure 7. Computed stream concentration of NTO $50 \mathrm{~m}$ downstream of the AIA, USMA, with $95 \%$ confidence bounds for uncertainty of soil HL compared to baseline conditions.

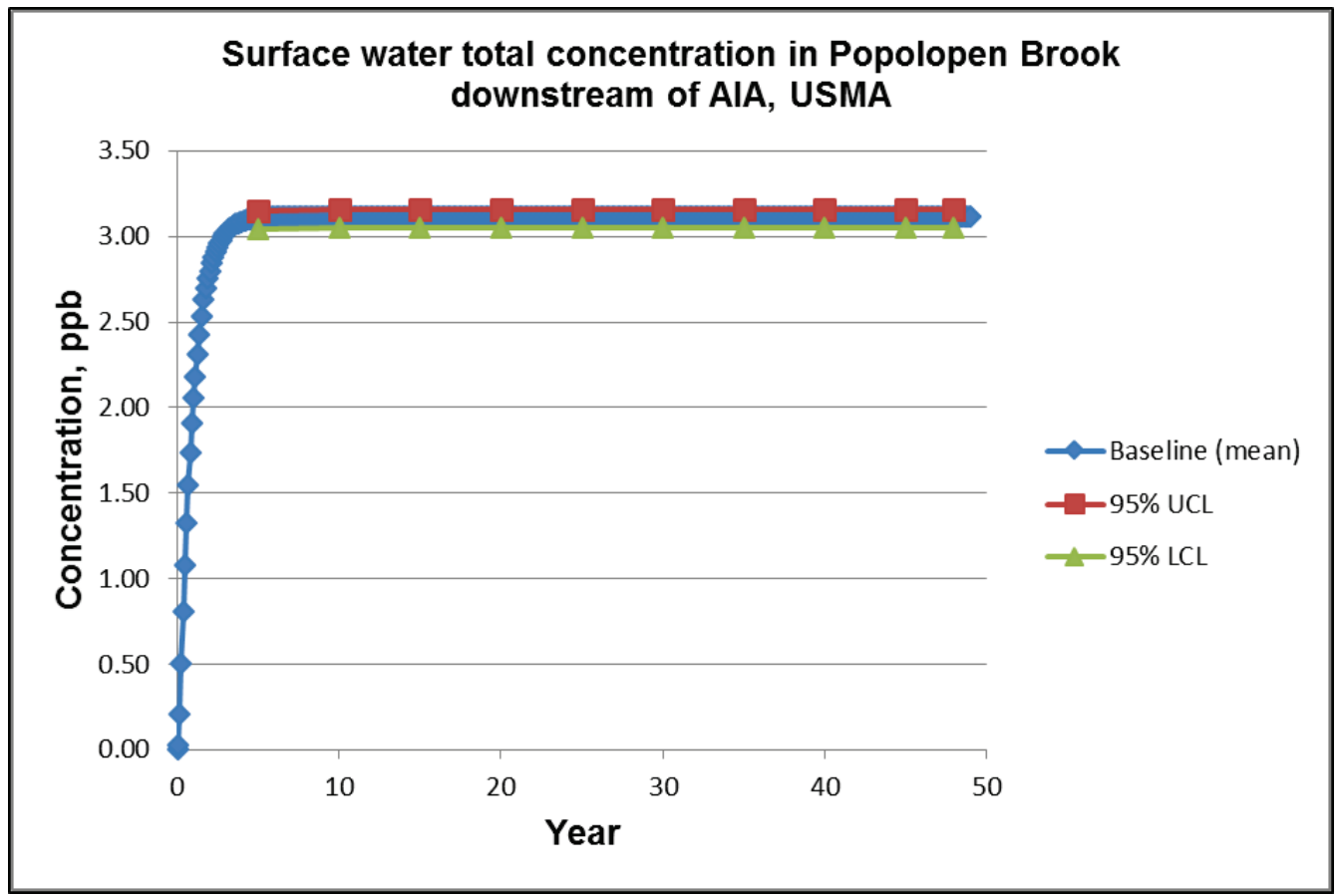

The sensitivity of stream NTO degradation rate at the second receptor location of 5,000 $m$ downstream of the AIA is very similar to that of DNAN. The rather high degradation rate of 1.0 per day results in a $0.68 \mathrm{ppb}$ decrease in steady-state stream concentration of NTO over 5,000 m compared with no degradation. It is concluded that stream concentrations of NTO are more sensitive to stream degradation rate than soil HL of NTO. The low sensitivity of stream concentrations to soil HL is due to a shorter soil residence time (compared to DNAN) coupled with higher soil HL of NTO. The stream travel time of NTO is the same as DNAN. The very wide range of stream degradation rate from none to one per day is the major driver resulting in significant sensitivity to stream degradation rate.

\subsubsection{Soil partitioning}

The sensitivity of stream NTO concentrations to NTO $K d$ values in soil was evaluated. Monte Carlo uncertainty analysis was conducted by varying only the soil NTO $K_{d}$ values and monitoring stream total NTO concentrations at the upstream station (50 $\mathrm{m}$ downstream of the AIA). A normal distribution was assumed with a mean soil NTO $K_{d}$ value of $0.41 \mathrm{~L} / \mathrm{kg}$ and upper and lower bounds of 0.72 and $0.29 \mathrm{~L} / \mathrm{kg}$ (see Table 3). The difference in the bound values divided by six resulted in a standard deviation of 0.072 
$\mathrm{L} / \mathrm{kg}$. All four values were entered into the $\mathrm{S} / \mathrm{U} \mathrm{UI}$, and the $\mathrm{S} / \mathrm{U}$ module was run for 50 iterations.

The results of the above S/U application look similar to the results plotted in Figure 7; thus exhibiting almost no sensitivity to soil NTO $K_{d}$ values. The sensitivity of $K_{d}$ values of NTO in water and sediments was evaluated by applying the baseline conditions with the maximum and minimum values for NTO shown in Table 4. The computed steady-state stream NTO concentrations were the same for both $K_{d}$ values, indicating insensitivity to varying stream NTO $K_{d}$ values.

\subsubsection{Conclusions}

Surface water stream NTO concentrations are nearly insensitive to soil HL. Stream NTO concentrations show about the same sensitivity to stream degradation rate as was found for DNAN. Stream NTO concentrations for this site are insensitive to NTO $K_{d}$ values in soil and stream.

\subsection{NQ sensitivity}

\subsubsection{Half-lives}

Monte Carlo uncertainty analysis was conducted by varying only the soil NQ HL values and monitoring stream total NQ concentrations at the upstream station (50 m downstream of the AIA). The mean soil HL for NQ is 1.0 year (see Table 5) with lower and upper bounds of 0.3 and 3.0 years. A $\log$ normal distribution was assumed for the uncertainty analysis. The HL values for NQ in Table 5 were converted to degradation rates as required by the Monte Carlo $\mathrm{S} / \mathrm{U}$ module by assuming a first order decay. Thus, the upper and lower bounds on degradation rate were set to 2.31 and 0.23 per year, respectively, within the S/U module UI. The mean log degradation rate was set to -0.1592 per year using the HL of 1.0 year and was entered into the S/U UI. The difference in the logs of the upper and lower degradation rates was divided by 6 to estimate the standard deviation log of 0.167 per year that was input in the S/U UI. The S/U module was executed for 50 iterations, which was enough to reach consistent results with the Latin Hypercube sampling procedure.

The results of the above S/U application are plotted in Figure 8 for baseline results and the upper and lower $95 \%$ confidence band associated with uncertainty of soil NQ HL. This figure shows that stream NQ concentra- 
tions are slightly sensitive to soil HL of NQ. Two deterministic runs were executed with the soil HL set to the upper and lower bounds of 3 and 0.3 years. The resulting steady-state stream concentrations of NQ were 3.12 and $2.42 \mathrm{ppb}$, respectively, which confirmed the fairly low sensitivity of stream NQ concentrations to soil NQ HL. NQ responds similarly to NTO due to its high solubility and relatively low $K_{d}$ values.

Figure 8. Computed stream concentration of NQ $50 \mathrm{~m}$ downstream of the AIA, USMA, with $95 \%$ confidence bounds for uncertainty of soil HL compared to baseline conditions.

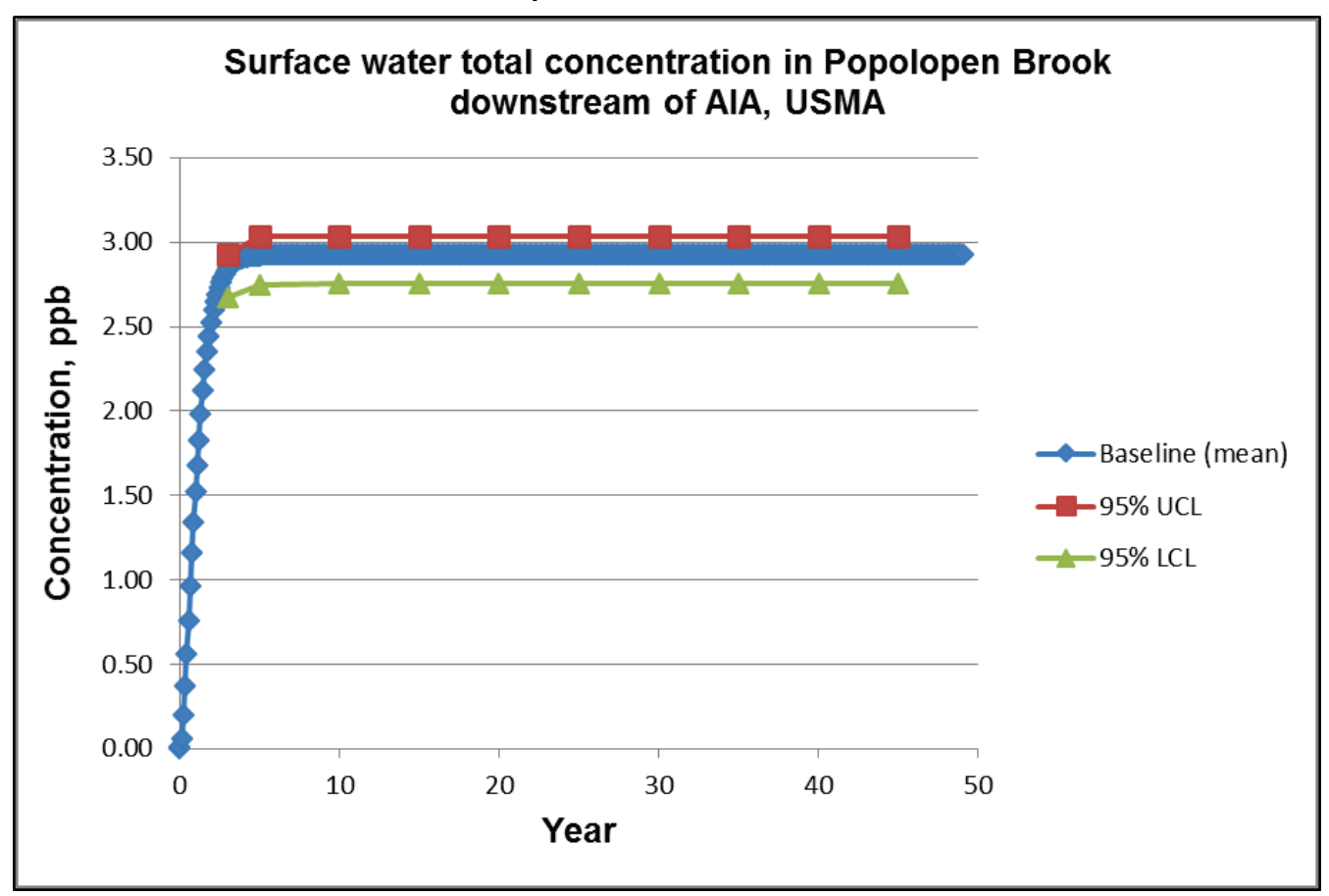

The sensitivity of stream NQ degradation rate at the second receptor location of 5,000 $m$ downstream of the AIA is very similar to that of DNAN and NTO. The rather high degradation rate of 1.0 per day results in a 0.64 ppb decrease in steady-state stream concentration of NQ over $5,000 \mathrm{~m}$ compared with no degradation. It is concluded that stream concentrations of NQ are more sensitive to stream degradation rate than soil HL of NQ. The low sensitivity of stream concentrations to soil HL is due to a shorter soil residence time (compared to DNAN) coupled with higher soil HL of NQ. The very wide range of stream degradation rate from none to 1 per day is the major driver resulting in higher sensitivity of stream degradation rate compared to soil HL. 


\subsubsection{Soil partitioning}

The sensitivity of stream NQ concentrations to NQ $K d$ values in soil was evaluated. Monte Carlo uncertainty analysis was conducted by varying only the soil NQ $K d$ values and monitoring stream total NQ concentrations at the upstream station (50 $\mathrm{m}$ downstream of the AIA). A normal distribution was assumed with a mean soil NQ $K_{d}$ value of $0.3 \mathrm{~L} / \mathrm{kg}$ (see Table 3 ) and upper and lower bounds of 0.6 and $0.1 \mathrm{~L} / \mathrm{kg}$. The difference in the bound values divided by 6 resulted in a standard deviation of $0.083 \mathrm{~L} / \mathrm{kg}$. All four values were entered into the $\mathrm{S} / \mathrm{U} \mathrm{UI}$, and the $\mathrm{S} / \mathrm{U}$ module was run for 50 iterations.

The results of the above $\mathrm{S} / \mathrm{U}$ application showed practically no sensitivity to NQ soil $K_{d}$ values. The baseline and 95\% confidence bands plotted on top of each other. The sensitivity of $K_{d}$ values of NQ in water and sediments was evaluated by applying the baseline conditions with the maximum and minimum values for NQ shown in Table 4. The computed steady-state stream NQ concentrations were the same for both $K_{d}$ values, indicating insensitivity to varying stream NQ $K_{d}$ values.

\subsubsection{Conclusions}

Surface water stream NQ concentrations are slightly sensitive to soil HL of NQ. Stream NQ concentrations show about the same sensitivity to stream degradation rate as was found for DNAN and NTO, with more sensitivity than soil HL. Stream NQ concentrations for this site are insensitive to NQ $K_{d}$ values in soil and stream.

\subsection{Summary}

Travel time in surface water, especially for flowing streams, is much less important than transit time in groundwater, due to surface water travel time being so short compared with groundwater. Soil residence time does affect receiving stream concentrations of EC when the EC degrades more rapidly in soil. However, soil residence time for the three EC that were studied is relatively short, thus resulting in lower effect on reducing stream concentrations compared with no degradation.

The sensitivity results obtained through the model applications for the three EC to AIA, USMA, are summarized in Table 7. Examination of Table 7 reveals that receiving stream DNAN concentrations are moderately sen- 
sitive to soil HL for DNAN, but NTO and NQ stream concentrations are almost insensitive to soil HL for NTO and NQ. This result is due to the longer residence time of DNAN in soil compared with NTO and NQ; this condition is caused by the higher soil $K_{d}$ value of DNAN. Longer soil residence time allows a greater amount of degradation in soil, thus lowering receiving stream concentrations. All three EC showed about the same sensitivity to stream degradation rate. The wide range in degradation rates (from zero to 1 per day) that was tested caused the moderate level of sensitivity. All three EC exhibited essentially no sensitivity to soil and stream $K_{d}$ values.

Table 7. Sensitivity of surface water stream concentrations for three EC to inputs for degradation and partitioning.

\begin{tabular}{|l||c|c||c|c||}
\hline \multicolumn{1}{|c|}{ EC } & Soil HL & $\begin{array}{c}\text { Surface } \\
\text { water } \\
\text { degradation } \\
\text { rate }\end{array}$ & Soil $K_{d}$ & $\begin{array}{c}\text { Surface } \\
\text { water } K_{d}\end{array}$ \\
\hline DNAN & Moderate & Moderate & Very low & Very low \\
\hline NTO & Very low & Moderate & Very low & Very low \\
\hline NQ & Low & Moderate & Very low & Very low \\
\hline \hline
\end{tabular}

It is concluded that generally surface water sites require much less accuracy for estimating soil and surface water EC degradation rates than required for vadose zone and groundwater. However, it is recognized that the importance of estimates for surface water degradation rates increases as the downstream distance of (and travel time to) the receptor location in the receiving stream increases, or as the residence time in the receiving standing surface water body (e.g., ponds and lakes) increases. Also, accurately estimating soil degradation rates of DNAN is more important than for NTO and NQ due to its longer soil residence time. The above results for the AIA site indicate that for the expected $K_{d}$ values of the three EC there is little need to accurately refine the EC soil and sediment $K_{d}$ estimates. Some work is needed to verify that the three $\mathrm{EC} K_{d}$ values for sediments are low and in the range of those shown in Table 4. 


\section{Summary and Conclusions}

TREECS $^{\mathrm{TM}}$ was applied to two study sites to evaluate the sensitivity of uncertain input properties for the fate of the three EC: DNAN, NTO, and NQ, which are components of the new insensitive munitions explosive formulation IMX-101. One study site, Demo Area 2 of MMR, featured groundwater, while the other study site, AIA of USMA, featured surface water. Two types of input properties were selected for a detailed study: degradation rate or half-life, HL, and water-to-soil and water-to-sediment adsorption partitioning distribution coefficients, or $K_{d}$ values. These inputs are regarded to be the most uncertain with a potentially high level of effect on EC fate. Literature was reviewed to provide estimates of the expected HL (or degradation rates) and $K_{d}$ values for the three EC, as well as the expected range in these values. These estimates were used to conduct simulations of the $\mathrm{EC}$ at each site, and the $\mathrm{EC}$ fate results (i.e., concentrations in receiving groundwater and surface water) were studied to draw conclusions regarding the sensitivity of results to these uncertain inputs.

The applications to Demo Area 2, MMR, which is a groundwater site, revealed the importance of soil residence time and transit time through the vadose zone and aquifer. The amount of constituent degradation in various media depends on the degradation rate (i.e., HL) in a medium and the time spent in that medium. The time spent in a medium is affected by the soil adsorption partitioning coefficient. Adsorption causes transport retardation. Simulation of a nondegrading and nonadsorbing tracer for this study site showed that the soil residence time and transit time through the aquifer (from vadose entry to receptor well) is only a few months, whereas the transit time through the vadose zone is approximately 14 years. Thus, the vadose zone is by far the most important medium for this site with regard to $\mathrm{EC}$ fate. However, the transit time through the aquifer can be much longer than through the vadose zone for other sites or other receptor locations.

The sensitivity results obtained through the model applications for the three EC to Demo Area 2, MMR, are summarized in Table 6. It is concluded that estimation of HL, particularly for vadose zone and groundwater, is critically important for the accuracy of model predictions of receiving groundwater concentrations. Furthermore, accurate estimation of HL is 
considerably more important than accurate estimation of $K_{d}$. However, it is recognized that $K_{d}$ values can affect the amount of influence of HL, where high $K_{d}$ values cause HL to exert more influence on receiving groundwater concentrations. Thus, the sensitivity of aquifer receiving well concentrations to HL in all media was greater for DNAN than for the other two EC due to the higher $K_{d}$ values of DNAN.

The applications to the AIA, USMA, which is a surface water site, revealed that travel time in surface water, especially for flowing streams, is much less important than transit time in groundwater, due to surface water travel time being so short compared to groundwater. Soil residence time does affect receiving stream concentrations of $\mathrm{EC}$ when the $\mathrm{EC}$ degrades in soil. However, soil residence time for the three EC that were studied is relatively short for this site, thus resulting in a modest effect on reducing stream concentrations compared with no degradation.

The sensitivity results obtained through the model applications for the three EC to AIA, USMA, are summarized in Table 7. It is concluded that generally, surface water sites require much less accuracy for estimating soil and surface water EC degradation rates than what vadose zone and groundwater require. However, it is recognized that the importance of estimates for surface water degradation rates increases as the downstream distance of (and travel time to) the receptor location in the receiving stream increases, or as the residence time in the receiving standing surface water body (e.g., ponds and lakes) increases. Also, accurately estimating soil degradation rates of DNAN is more important than for NTO and NQ, due to its longer soil residence time.

Given the expected low $K d$ values of the three EC, there is minimal need to accurately refine the EC $K_{d}$ estimates, particularly for surface water receptors. Some work is needed to verify that the three EC $K_{d}$ values for sediments are low and in the range of those shown in Table 4.

The results of the study lead to the conclusion that future research should focus predominantly on determining natural degradation rates of EC in surface soil, vadose zone (partially water-saturated groundwater), and water-saturated groundwater. Vadose zone and groundwater should receive higher priority surface soil. It is expected that EC degradation rates are not only EC-specific, but are also affected by site-specific media characteristics, thus complicating their estimation. 


\section{References}

ATC (U.S. Army Aberdeen Test Center). 2004. Addendum 1 Final report for the USMA small arms range environmental screening level assessment. Report number ATC-8710. Aberdeen Proving Ground, MD: ATC.

Brannon, J., C. Price, S. Yost, C. Hayes, J. Mirecki, and B. Porter. 2004. Fate and transport parameters for firing range residues. In Distribution and Fate of Energetics on DoD Test and Training Ranges: Interim Report 4. ERDC TR-044. Vicksburg, MS: US Army Engineer Research and Development Center.

Dontsova, K., S. Taylor, R. Pesce-Rodriguez, M. Brusseau, J. Arthur, N. Mark, M. Walsh, J. Lever, J. Šimůnek. 2014a. Dissolution of NTO, DNAN, and insensitive munitions formulations and their fates in soils. ERDC/CRREL TR-14-23. Hanover, NH: U.S. Army Engineer Research and Development Center.

Dontsova, K., M. Brusseau, J. Arthur, N. Mark, S. Taylor, J. Lever, M. Walsh, R. PesceRodriguez, and J. Šimůnek. 2014b. Dissolution of NTO, DNAN, and insensitive munitions formulations and their fate in soils. Chapter 5 in JANNAF Workshop Proceedings - Fate, Transport and Effects of Insensitive Munitions: Issues and Recent Data. Mark Johnson, editor. Environmental Restoration Report. Aberdeen Proving Ground, MD: U.S. Army Public Health Command.

Dortch, M. S., S. Fant, and J. A. Gerald. 2007. Modeling fate of RDX at demolition area 2 of the Massachusetts Military Reservation. J. of Soil and Sediment Contamination 16(6): 617-635.

Dortch, M. S. 2012. Validation applications of the Training Range Environmental Evaluation and Characterization System (TREECS ${ }^{\mathrm{TM}}$ ). ERDC/EL TR-12-3. Vicksburg, MS: U.S. Army Engineer Research and Development Center.

Dortch, M. S., B. E. Johnson, and J. A. Gerald. 2013. Modeling Fate and Transport of Munitions Constituents on Firing Ranges. Soil and Sediment Contamination: An International Journal 22(6): 667-688.

Dortch, M. S. 2015. Evaluation of uncertainty of constituent input parameters for modeling the fate of RDX. ERDC/EL TN-15-2. Vicksburg, MS: U.S. Army Engineer Research and Development Center.

Dortch, M.S., B.E. Johnson, and E.J. Weber. 2017. Field demonstration and validation of TREECS $^{\mathrm{TM}}$ and CTS for the risk assessment of contaminants on DoD ranges. ERDC/EL TR-17-5. Vicksburg, MS: U.S. Army Engineer Research and Development Center.

Environmental Analytical Chemistry and Applied Ecotoxicology Groups. 2012. Environmental fate and ecological impact of emerging energetic chemicals (DNAN and its Amino-Derivatives, NTO, NQ, FOX-7, and FOX-12). Annual Report 2011-2012, NRC \#53412. Montréal, Québec: Biotechnical Research Institute, National Research Council of Canada. 
Field, J., R. Sierra, C. Olivares, S. Cameron, M. Krzmarzick, H. Garcia, L. Abrell, J. Chorover, R. Khatiwada, and J. Coffey II. 2014. Biotransformation of insensitive munitions components in soil microbial cultures. Chapter 9 in JANNAF Workshop Proceedings - Fate, Transport and Effects of Insensitive Munitions: Issues and Recent Data. Mark Johnson, editor. Environmental Restoration Report. Alexandria, VA.

Fuller, E. N., P. D. Schettler, and J. C. Giddings. 1966. A new method for prediction of binary gas-phase diffusion coefficients. Ind. Eng. Chem. 58: 19-27.

Haag, W. R., R. Spanggord, T. Mill, R. T. Podoll, T. W. Chou, D. S. Tse, and J. C. Harper. 1990. Aquatic environmental fate of nitroguanidine. Environ. Toxicol. Chem. 9: 1359-1367.

Hayduk, W., and H. Laudie. 1974. Prediction of diffusion coefficients for non-electrolysis in dilute aqueous solutions, AICHe J. 20, 611-615.

Kaplan, D., and A. Kaplan. 1985. Degradation of nitroguanidine. Technical Report NATICK/TR-85/047. Natick, MA: U.S. Army Natick Research and Development Center.

Krzmarzick, M. J., R. Khatiwada, C. I. Olivares, L. Abrell, R. Sierra-Alvarez, J. Chorover, and J. A. Field. 2015. Biotransformation and degradation of the insensitive munitions compound, 3-nitro-1,2,4-triazol-5-one, by soil bacterial communities. Environ. Sci. \& Technol. 49: 5681-5688.

Mulherin, N., T. Jenkins, and M. Walsh. 2005. Stability of nitroguanidine in moist, unsaturated soils. ERDC/CRREL TR-05-2. Hanover, NH: U.S. Army Engineer Research and Development Center.

Perreault, N. N., D. Manno, A. Halasz, S. Thiboutot, G. Ampleman, and J. Hawari. $2012 a$. Aerobic biotransformation of 2,4-dinitroanisole in soil and soil Bacillus sp. Biodegradation. 23: 287-295.

Perreault, N. N., A. Halasz, D. Manno, S. Thiboutot, G. Ampleman, and J. Hawari. 2012b. Aerobic mineralization of nitroguanidine by Variovorax strain $\mathrm{VC} 1$ isolated from soil. Environ. Sci. Technol. 46: 6035-6040.

Rao, B., W. Wang, Q. Cai, T. Anderson, and B. Gu. 2013. Photochemical transformation of the insensitive munitions compound 2,4-dinitroanisole. Sci. of the Total Environ. 443: 692-699.

Richard, T., and J. Weidhaas. 2014a. Biodegradation of IMX-101 explosive formulation constituents: 2,4-dinitroanisole (DNAN), 3-nitro-1,2,4-triazol-5-one (NTO), and nitroguanidine. J. Hazardous Materials 280: 372-379.

Richard, T., and J. Weidhaas. 2014b. Dissolution, sorption, and phytoremediation of IMX-101 explosive formulation constituents: 2,4-dinitroanisole (DNAN), 3-nitro1,2,4-triazol-5-one (NTO), and nitroguanidine. J. Hazardous Materials. 280: 561-569. 
Salter-Blanc, A., E. Bylaska, E. Ritchie, and P. Tratnyek. 2013. Mechanisms and kinetics of alkaline hydrolysis of the energetic nitroaromatic compounds 2,4,6trinitrotoluene (TNT) and 2,4-dinitroanisole (DNAN). Environ. Sci. Technol. 47: 6790-6798.

Taylor, S., K. Dontsova, S. Bigl, C. Richardson, J. Lever, J. Pitt, J. Bradley, M. Walsh, and J. Šimůnek. 2012. Dissolution rate of propellant energetics from nitrocellulose matrices. ERDC/CRREL TR-12-9. Hanover, NH: U.S. Army Engineer Research and Development Center.

Williams, R., W. Sisk, and A. MacGillivray. 1989. Degradation of nitroguanidine wastewater components in soil. Environ. Toxicol. \& Chem. 8: 469-475. 


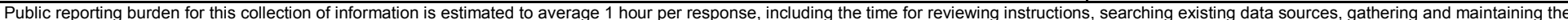

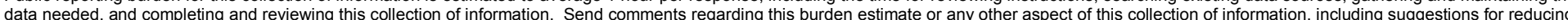

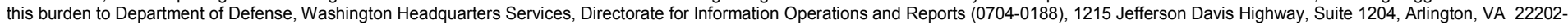

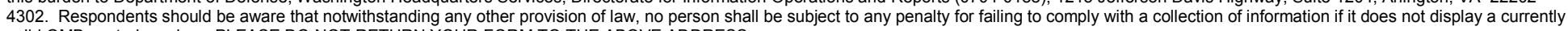
valid OMB control number. PLEASE DO NOT RETURN YOUR FORM TO THE ABOVE ADDRESS.

\begin{tabular}{l|c}
$\begin{array}{l}\text { 1. REPORT DATE (DD-MM-YYYY) } \\
\text { May } 2017\end{array}$ & 2. REPORT TYPE \\
\hline
\end{tabular}

4. TITLE AND SUBTITLE

Evaluation of Uncertainty in Constituent Input Parameters for Modeling the Fate of IMX-101 Components

\section{AUTHOR(S)}

Mark S. Dortch and Billy E. Johnson

\section{DATES COVERED (From - To)}

\section{5a. CONTRACT NUMBER}

5b. GRANT NUMBER

5c. PROGRAM ELEMENT NUMBER

5d. PROJECT NUMBER

ER201435

5e. TASK NUMBER

\section{5f. WORK UNIT NUMBER}

\section{PERFORMING ORGANIZATION NAME(S) AND ADDRESS(ES)}

U.S. Army Engineer Research and Development Center

Environmental Laboratory

3909 Halls Ferry Road

8. PERFORMING ORGANIZATION REPORT NUMBER

Vicksburg, MS 39180

\section{SPONSORING / MONITORING AGENCY NAME(S) AND ADDRESS(ES)}

Environmental Security Technology

Certification Program (ESTCP)

4800 Mark Center Drive, Suite 17D08

Alexandria, VA 22350-3605

ERDC/EL TR-17-7

10. SPONSOR/MONITOR'S ACRONYM(S)

ESTCP

11. SPONSOR/MONITOR'S REPORT NUMBER(S)

\section{DISTRIBUTION / AVAILABILITY STATEMENT}

Approved for public release; distribution is unlimited.

\section{SUPPLEMENTARY NOTES}

\section{ABSTRACT}

The Training Range Environmental Evaluation and Characterization System (TREECS ${ }^{\mathrm{TM}}$ ) was applied to a groundwater site and a surface water site to evaluate the sensitivity of the uncertain input properties (degradation rates and water-to-soil and water-to-sediment adsorption partitioning distribution coefficients, or $K d$ values) on the fate of three emerging constituents (EC): DNAN, NTO, and NQ. These three EC are components of the new insensitive munitions explosive formulation IMX-101. The authors reviewed the literature and provided estimates of the expected degradation rates and $K d$ values for the three EC. EC simulations were conducted for each site, and predicted concentrations in receiving groundwater and surface water were studied to draw conclusions regarding the sensitivity of the results to these uncertain inputs.

The applications revealed that, in general, surface water sites require much less accuracy for estimating soil and surface water EC degradation rates than do vadose zone and groundwater. Given the expected low $K d$ values of the three EC, there is minimal need to accurately refine the EC $K d$ estimates, particularly for surface water receptors. The authors concluded that future research should focus predominantly on determining degradation rates of EC groundwater, vadose zone, and surface soil, in that order of priority.

\section{SUBJECT TERMS}

Modeling fate of emerging constituents, Training Range Environmental Evaluation and Characterization System, DNAN, NTO, NQ, Rifle-ranges, Bombing and gunnery ranges, Explosives, Military, Soil pollution. Groundwater-Pollution, Insensitive Munitions

\begin{tabular}{|c|c|c|c|c|c|}
\hline \multicolumn{3}{|c|}{ 16. SECURITY CLASSIFICATION OF: } & 17. LIMITATION & 18. NUMBER & 19a. NAME OF RESPONSIBLE PERSON \\
\hline $\begin{array}{l}\text { a. REPORT } \\
\text { Unclassified }\end{array}$ & $\begin{array}{l}\text { b. ABSTRACT } \\
\text { Unclassified }\end{array}$ & $\begin{array}{l}\text { c. THIS PAGE } \\
\text { Unclassified }\end{array}$ & SAR & 56 & $\begin{array}{l}\text { 19b. TELEPHONE NUMBER (in- } \\
\text { clude area code) }\end{array}$ \\
\hline
\end{tabular}

